\title{
Tendencias favorables o adversas a la formación de un sistema regional latinoamericano
}

En este trabajo se intenta avanzar en el examen de las tendencias favorables o adversas a la formación de un subsistema regional latinoamericano que, a través de una presencia propia y un comportamiento coherente, pueda mejorar su participación en el sistema internacional. ${ }^{x}$

En efecto, el fucuro de América Latina se encuentra condicionado por la posición que ésta ocupe en el contexto mundial. Esta posición, a su vez, depende del grado de coherencia de las políticas exteriores de los países de la región. Las relaciones de los países latinoamericanos entre sí, el grado de control que ejerzan sobre sus recursos naturales, sus relaciones comerciales con el resto del mundo, sus condiciones de acceso a la inversión y a la tecnología extranjeros y el comportamiento de las corporaciones multinacionales constituyen otras tantas variables que inciden sobre el porvenir de la región. Si América Latina no fortalece su capacidad para influir sobre dichos factores, no podrá alentar esperanza alguna de reducir su dependencia externa, mejorar su posición negociadora frente al resto del mundo, ni adoptar modelos de desarrollo que permitan a los latinoamericanos 'utilizar mejor sus recursos propios y' retener una porción mayor de los frutos de ese proceso.

Para actuar sobre las variables anteriormente señaladas es necesario conocerlas. Lamentablemente, el estudio de las relaciones internacionales no ha alcanzado todavía en la región un grado de desarrollo que permita analizar estos factores con la profundidad requerida. En adición a la valiosa y continua contribución efectuada por organismos regionales y subregionales, algunos intelectuales latinoamexicanos han producido enfoques teóricos y esquemas interpretativos extremadamente lúcidos y además coherentes con los. intereses vitales de esta parte del mundo, pero su aporte no se ha enmarcado dentro de un conjunto de esfuerzos más amplio y sistemático ni ha alcanzado un grado de desagregación adecuado, condiciones necesarias para que sus percepciones tengan una mayor proyección en el plano de la verificación empírica y de la acción política.

IVer Luciano Tomassini, Toward a Latin American Nationalism, en The World today (Chatham House), diciembre 1969. 
En efecto, es mucho lo que falta por hacer para acrecentar el conocimiento sistemático de los intereses, las políticas y los medios de acción de las naciones industrializadas, de las cuales los países latinoamericanos dependen tan estrechamente; para identificar en forma rigurosa los intereses de los países latinoamericanos y los instiumentos más aptos para promoverlos; para examinar las ventajas que podrían derivarse de un mayor grado de integración y cooperación regional; para evaluar los resultados de las políticas perseguidas en estas materias, en el pasado, y elaborar alternativas; para desarrollar fuentes de información propias, en lugar de depender de fuentes extrarxegionales, y para desenvolver un marco analítico adecuado.

El insuficiente grado de conocimiento acerca de estos problemas ha llevado con frecuencia a los países latinoamericanos a desperdiciar las oportunidades, de suyo escasas, para fortalecer el proceso de cooperación regional, adquirir más influencia en los mecanismos internacionales existentes, ejercer mayor control sobre el flujo de recursos externos, ganar ventajas en áreas y mercados no tradicionales, crear nuevas solidaridades internacionales, acentuar su presencia en la solución de los problemas mundiales que los afectan directa o indirectamente, y acrecentar su movilidad internacional en el mundo multipolar del último tercio del Siglo xx.

La hipótesis que sirve de base a este trabajo consiste en que el mejoramiento de la participación internacional de América Latina depende, fundamentalmente, del grado de unidad que alcancen los países de la región y del grado de armonización de sus políticas exteriores. De allí la importancia de examinar las tendencias favorables o adversas a este tipo de evolución, en cuya consolidación será esencial el papel que puedan desempeñar los procesos de integración que se están desarrollando en América Latina, y su eventual convergencia.

El trabajo toma como punto de partida una tesis y plantea una interrogante. La tesis consiste en que, alrededor de 1970, cambió fundamentalmente el patrón que inspiró las relaciones internacio.. nales de América Latina durante los veinticinco años precedentes. En esta aseveración no se pretende anticipar la dirección de tal cambio. En todo caso, parecería prudente reconocer que éste apunta hacia una mayor independencia de las politicas exteriores de los países latinoamericanos, hacia una mayor diversificación de las mismas, o hacia lo que podría ser una combinación de ambas interpretaciones, a saber, una "diversificación de sus vínculos de dependencia". La interrogante se refiere a la medida en que estos cambios podrían favorecer u obstaculizar la formación de un subsistema regional latinoamericano sobre bases cooperativas o, para ser 
Luciano Tomassini / Tendencias farorables o adversas a la- formación...

más precisos, de un subsistema regional en que las relaciones de cooperación predominan sobre las relaciones de conflicto.

1. EL ESTUDIO DE LAS RELACIONES INTERNACIONALES DE LAS REgIONES

El examen de estas tendencias puede llevarse a cabo dentro de un marco analítico bien conocido. Dentro de la teoría contemporánea de las relaciones internacionales, el análisis de "la política internacional de las regiones", o de la emergencia de "subsistemas regionales" que operan dentro del contexto más amplio del sistema internacional, tiende a ocupar un lugar cada vez más clestacado.

Hasta hace aproximadamente veinte años, las ciencias sociales relegaron la preocupación por. las regiones a los famosos "estudios de área", de origen predominantemente anglosajón, con los cuales se pretendía dar una base de sustentación tanto al empirismo in. telectual como a los intereses coloniales de las potencias industrializadas. A fines de la década del cincuenta se realizan los primeros intentos de imprimir a estos estudios un alcance comparativo que, mediante la aplicación de un marco de referencia homogéneo al análisis cle las distintas regiones, permitiera identificar las funciones comunes a los distintos sistemas y las diferencias observables en el cumplimiento de dichas funciones como consecuencia de las peculiaridades propias de cada uno de ellos². Otrá línea de reflexión condujo a analizar las agrupaciones regionales como sujetos potenciales de las relaciones internacionales, situadas entre los estados y el sistema internacional. ${ }^{3}$

Tal vez los primeros ensayos en esta dirección se originaron en

2Una de las obras pioneras en esta línea de análisis es la de Almond y Coleman, The politics of the Developing Areas, prologado en diciembre de 1959.

3EI papel del "regionalismo" ya había sido reconocido en los estudios relativos a la "organización internacional", de tradición juridicista, y parcialmente consagrado en el capítulo VII de la Carta de las Naciones Unidas dedicada a los "acuerdos y organismos regionales". Estos antecedentes, sin embargo, resultan inadecuados en la medida en que analizan el fenóneno regional exclusivamente dentro del marco de las organizaciones formales. Es interesante observar como analistas modernos, como el profesor David Singer, incurren en esta limitación cuando formulan una distinción entre (a) coaliciones o alianzas, y (b) organizaciones intergubernamentales, distinción en que no hay Ingar para subsistemas regionales que no se expresan a través de organizaciones formales, y que se encuentra muy cerca de la concepción implicita en los estudios clásicos. Ver de este autor The Global System and its Subsystem: in Developmental riew, en James $N$. Roseman (cditor), Linkage politics: essay's on the convergences of nalional and inlernational systems, 1969. 
los trabajos de Karl Deutsch y otros, sobre la comunidad del área del Atlántico Norte, y de Ernst B. Haas, sobre la unificación europea, de 1957 y 1958, respectivamente. Pero hubo que esperar diez años para que hiciera su aparición un conjunto de estudios consagrados al examen de estos problemas clesde un punto de rista más amplio. En ellos la atención se desviaba no solamente desde Europa y el Atlántico Norte hacia otras regiones del mundo sino también desde los modelos funcionalistas, primordialmente interesados en explicar los movimientos formales de integración que se estaban desarrollando en Europa y en otros lugares, hacia enfoques más pragmáticos que buscaban descubrir regulariclades en la interacción $\mathrm{y}$ uniformidades en la politica externa de una agrupación de países que, de esta manera, podía considerarse un "subsistema regional" -para cuya emergencia la integración pasaba a ser un elemento*. Surge así la posibilidad de considerar la región como una unidad de análisis que participa con identidad propia en el sistema internacional y que incluso, en cierta medida, es capaz de desarrollar una política exterior de alcance regional.

Naturalmente, esta perspectiva no se debe a los avances experimentados en el análisis académico de la vida internacional, sino en las tendencias al regionalismo claramente observables en el mundo contemporáneo. Estas tendencias son, en gran parte, una consecuencia de los procesos de nacionalismo, descolonización e intensificación de las relaciones de interdependencia entre todos los países del mundo, que se han venido desarrollando a lo largo del Siglo $\mathrm{xx}$ y se han agudizado a partir de la Segunda Guerra Mundial. El impacto combinado de estos procesos ha producido, entre otros, tres efectos fundamentales. Ha ampliado el escenario mundial, triplicando el número de naciones que al terminar la última conflagración participaba en la comunidad internacional, y ligando la suerte de cada una de ellas a la de las regiones aparentemente más remotas. Ha diversificado los centros del poder mundial, desde las épocas de la Santa Alianza y del "concierto europeo", no obstante las tendencias hacia una estratificación internacional mucho más marcada que en el pasado. Ha forzado a los países a intensificar los procesos de coordinación y consulta en sus relaciones recíprocas y' a perseverar en la negociación como el medio más adecuado para armonizar sus objetivos y dirimir sus disputas. Estos efectos estimulan la presencia y actuación de los subsistemas regionales en la vida internacional.

4Entre las obras colectivas más importantes que iniciaran esta linea de análisis, cabe destacar las de James N. Roseman, ya citada; Joseph S. Nye (editor), International regionalism. Readings, 1968; Louis J. Cantori y Steven L. Spiegel (cditores), The International Politics of Regions: a comparative approach, 1970. 
Como consecuencia de ello, tanto la política exterior, como las relaciones recíprocas y los nexos de dependencia entre los distintos países tienden a definirse sobre bases regionales en un número creciente de casos, como ocurre con los paises de la Comunidad Eco. nómica Europea y de la Europa del Este, del Acuerdo de Cartagena y del Medio Oriente.

También existen contracorrientes. Unas adoptan la forma de procesos encaminados a la integración vertical de economías industrializadas con economías en desarrollo, como se advierte en el hecho de que desde la Segunda Guerra Mundial no haya cesado de aumentax la proporción del comercio mundial que se realiza en virtud de regímenes preferenciales, y muy particularmente en el caso de la CEE a partir de su ampliación, en enero de 1972, acompañada de la formación de una zona europea de libre comercio entre la CEE y los cinco países miembros de la AELI que no se incorporaron; la ampliación de la política mediterránea de la Comunidad que, aunque con distintas modalidades, tienen un carácter preferencial y discriminatorio; la revisión del régimen de asociación que existía entre la Comunidad y los países africanos y Malgache, según la Convención de Yaoundé, que acentúa el carácter preferencial de sus relaciones, y la extensión del régimen de asociación a los países miembros del Commonwealth Británico. Otras contracorrientes se refieren a formas niás o menos agresivas de integración funcional o sectorial, cuyo ejemplo más vigoroso lo proporciona la OPEP, experiencias que abren la posibilidad de que la geografía económica $y$ la geografía política se entrecrucen o entren en conflicto. Una tercer contracorriente se refiere a agrupaciones de carácter horizontal en que las relaciones de conflicto parecen prevalecer sobre las de cooperación, como en el caso del Oriente Medio.

De cualquier forma, la emergencia de subsistemas regionales establecido sobre bases cooperativas podrían ser la principal reacción del sistema internacional en un mundo que parece encaminarse hacia una situación de congelamiento de las relaciones de poder, y el desafío más importante a la consolidación o ensanchamiento de la brecha que separa a países pobres y países ricos dentro del presente régimen de estratificación internacional. De allí que sea de gran interés, en el caso de América Latina, examinar las tendencias favorables o adversas a la formación de un subsistema regional.

Para hacerlo, se han escogido tres variables principales: (a) el grado y forma en que los países que integran la región perciben su identidad en el contexto internacional; (b) el grado de coherencia y coordinación existente entre las politicas exteriores de los países de la región, y (c) el grado y signo de la interacción "existente entre 
estos países, con énfasis en el predominio de las relaciones de cooperación sobre las relaciones de conflicto.5

2. LAS RELAGIONES INTERNACIONALES DE AMÉRICA LATINA ANTES Y DESPUÉS DE 1970

Como se ha señalado, el examen de las tendencias favorables o adversas a la formación de un subsistema regional latinoamericano debe realizarse dentro cle una perspectiva histórica, tomando como punto de partida el cambio ocurrido en las relaciones internacionales de la región alrededor de 1970.

A partir del término de la Segunda Guerra Mundial, las relaciones internacionales de la región quetlaion definidas por un acontecimiento fundamental: el estallido de la guerra fría entre los principales vencedores de esa contienda.

Ya en 1940 el secretario de estado norteamericano, Cordell Hull, había tratado de asegiurar la "neutralidad activa" de los países latinoamericanos frente al conflicto armado. Debe recordarse que, hasta bien adentrada la guerra, los lazos tradicionales entre Europa y los países latinoamericanos, la fuerte presencia de Alemañia (y en menor medida, Italia) en algunos de ellos y la existencia de activos movimientos pro fascistas en varios países de la región, tendieron a provocar el desdoblamiento de sus lealtades. Durante ese periodo, tanto las potencias del eje como los aliados pudieron competix para obtener la colaboración de los países latinoamericanos, o al menos para impedir que el enemigo usufructuara de ella. En cambio, en el conflicto planteado entre las potencias occidentales y la Unión Soviética al terminar la guerra, fue incuestionable el alineamiento de los países latinoamericanos junto a los primeros por su adhesión a los valores de la civilización occiclental, la presencia de gobiernos conservadores en buena parte de ellos y la disposición de los Estados Unidos a intervenir en resguardo de la seguridad hemisférica. El Tratado Interamericano de Asistencia Reciproca, que suscripto en 1947 adquirió celebridad por haber servido de modelo a los de la OTAN, el CENTO y el GEATO, y el establecimiento de la Organización de Estados Americanos, el siguiente año, dieron un marco formal a este férreo alineamiento dentro del contexto hemisférico. Este mismo alineamiento se expresó en el ámbito de las Naciones Unidas, en donde por esa época los rotos latinoamericanos

5 La definición más precisa de cada una de estas variables, y su verificación, se intentan en las secciones 3,4 y 5 , respectivamente. 
apoyaron las posiciones de los Estados Unidos, en los enfrentamientos de este país con la Unión Soviética.

El hecho es que en el lapso comprencliclo entre la Conferencia de Chapultepec sobre la Guerra y la Paz de 1945 y la IX Conferencia de Estaclos Americanos celebrada en Bogotá en 1948, pasando por la Conferencia sobre el Mantenimiento de la Paz y la Seguridad Hemisférica, América Latina quecló sólidamente adscrita al área de seguridad del mundo occidental. ${ }^{6}$

La tesis norteamericana consistía en asignar prioridad a la reconstrucción europea. Si acaso podía vislumbrarse una segunda prioridad, ésta estaba vinculada al reordenamiento de los asuntos en el Extremo Oriente. Se trataba de las dos regiones críticas desde el punto de vista de la guerra fría. Los Estados Unidos no podían colaborar al mismo tiempo en la reconstrucción europea y el mantenimiento de la seguridad en el Oriente Asiático, por una parte, $y^{\prime}$ el desarrollo del Tercer Mundo, por la otra. En el caso de América Latina, esta tesis se veía avalada por la saludable situación de reservas monetarias conque los países de la región habían emergido del período bélico. En todo caso, si estos países enfrentaban problemas económicos, podrían resolverlos satisfactoriamente atràyendo el capital privado. Los países latinoamericanos, por su parte, nunca dejaron de dar relevancia a sus dificultades económicas. Habiendo tenido que vender sus productos durante la guerra en un mercado controlado, tenían ahora que reponex sus equipos sobreutilizados, comprándolos en un mercado libre. Y'a en la Conferencia de Río de Janeiro, Argentina, Cuba, Chile y México plantearon la necesidad de que se discutiera el problema de la cooperación económica. El delegado de Cuba llegó a proponer que las disposiciones del Tratado de Río de Janeiro prohibieran las "amenazas y' agresiones de carácter económico"?. En respuesta a estas inquietudes, una resolución encomendó al Consejo Interamericano Económico y Social la preparación de una propuesta con base en la cual la IX Conferencia de Estados Americanos convocaría una Conferencia Económica en la segunda mitad de 1948. Esta reunión no fue convocada.

La oportunidad para hacerlo sólo vino a presentarse con ocasión de la X Conferencia de Estados Americanos, celebrada en Caracas, en marzo de 1954. En ella se procuraba obtener una declaración conjunta de los gobiemos latinoamericanos en el sentido de que la

6Entre la literatura reciente sobre la evolución de las relaciones interamericanas, ver especialmente Gordon Connell-Smith, The Inler-American System, 1966. Federico G. Gil, Latin American-United States Relations, 1971; Jerome Levinson y' Juan de Onis, The Alliance which lost its zua.j', 1971.

TArthur Thitaker, Rio and Bogotá; Panamerican perspectives, en Interamerican Economic affairs $I / 3$ (1947), pág. 27. 
instauración de un gobierno dominado por el Partido Comunista en cualquier pais del Continente representaba una amenaza a la seguridad del hemisferio y en consecuencia, de acuerdo con las disposiciones del Tratado de Río de Janeiro, podía dar lugar a una acción colectiva. El propósito de esta resolución era permitir la intervención contra el régimen del coronel Jacobo Arbens en Guatemala. Representó en esa oportunidad a los Estados Unidos el secretario de estado John Foster Dulles. La resolución fue aprobada, pero el precio que se debió pagar por ella fue la convocatoria de la Conferencia Económica anteriormente prometida.

La Conferencia se celebró en Quitandinha, Brasil, en noviembre de 1954 dentro del marco de CIES. Puede decirse que en ella hicieron su "estreno de sociedad" las principales ideas elaboradas clesde su creación, al final de la década anterior, por la Comisión Económica para América Latina de las Naciones Unidas (CEPAL), bajo el liderazgo de su secretario ejecutivo, doctor Raúl Prebisch. Los trabajos preparatorios realizados por la CEPAL para la Conferencia de Quitandinha fueron canalizados a través de un Comité de Expertos, cuyo presidente fue el senador chileno Eduardo Frei Montalva y cuyo relator fue el economista colombiano Carlos Lleras Restrepo. Las grandes tesis que habrian de inspirar en buena parte las políticas de desarrollo de los países latinoamericanos en años venideros incluían la necesidad de un vigoroso programa de coopexación externa, principalmente mediante la adopción de mecanismos de estabilización de precios de los productos primarios y el establecimiento de un fondo interamericano para el financiamiento del desamollo. Aunque en la reunión prevaleció la posición de Ios Estados Unidos representado por el secretario del Tesoro, George Humphrey, que tendía a cifrar la solución de los problemas del desarrollo en la atracción del capital privado extranjero mediante políticas adecuadas en lo interno, aquellas propuestas constituyeron las bases a partir de las cuales algunos años más tarde se remozaría el sistema interamericano.

Una vez más fue necesario esperar que la ocasión se presentara. En este caso, la oportunidad la proporcionó la gixa por América Latina del vicepresidente Nixon, de los Estados Unidos, y las visitas subsiguientes del subsecretario de estado para América Latina, Roy Rubottom y el propio secretario de estado de los Estados Unidos, John Foster Dulles, al presidente del Brasil, Juscelino Kubistchek, en 1958. En esta última entrevista, el presidente del Brasil sosturo que la intranquilidad y la violencia que habian estallado en algunos países de la región no podían ser atacadas con medidas de seguridad sino que eran expresión de un malestar más profundo, que encontraba sus raices en las condiciones económicas y sociales en que vivía 
la gran mayoría de la población, y propuso el lanzamiento de un drástico programa de cooperación para el desarrollo que en esa ocasión bautizó como Operación Panamericana.s

Los planteamientos de la Operación Panamericana habían de ser analizados en una reunión de Ministros de Relaciones Exteriores que se celebró en Washington, en setiembre de 1958. La reunión fue precedida del anuncio efectuado en una sesión especial del GIES por el subsecretario de estado, señor Douglas Dillon, en el sentido de que los Estados Unidos estaban preparados para participar en una organización financiera regional, y acompañada de medidas encaminadas a asegurar la adhesión de los Estados Unidos al Convenio Internacional del Cafés. La Conferencia de Cancilleres estableció el denominado Comité de los 21, encargado de implementar la Operación Panamericana. Estos pasos, conjuntamente con la entrada de Fidel Castro en La Habana el 5 de enero de 195910, representan el comienzo de un cambio en las relaciones interamericanas, cambio que conduciría a la Alianza para el Progreso.

¿Cuál fue el alcance del cambio que la Alianza para el Progreso imprimió a las relaciones interamericanas? Desde Iuego, que ella no alteró la adscripción de América Latina al hemisferio occidental ni su forma de inserción en el sistema internacional. En cambio, dentro del contexto de las relaciones hemisféricas, la Alianza para el Progreso significa, en primer lugar, que los Estados Unidos asignan a sus vecinos al sur del Río Grande una prioridad de que América Latina antes no disfrutaba; en segundo lugar, que dentro de esta mayor importancia atribuida a América Latina, los Estados Unidos deciden encarar la solución de los problemas económicos y sociales que vive la región en lugar de privilegiar los aspectos relacionados con la seguridad hemisférica; en tercer lugar, que en este vasto programa de cooperación para el desarrollo, los Estados Unidos recogen gran parte de los conceptos $\mathrm{y}$ aspiraciones proclamados por los propios países latinoamericanos.

sJerome Levinson $y$ Juan de Onis, op. cit., pág. 45.

9Al proponer la creación de una agencia de desarrollo para el Medio Oriente con la participación de su país, el presidente de los Estados Unidos habia aceptado la posibilidad de establecer instituciones regionales de financiamiento. Con respecto a los antecedentes de la creación del BID, ver especialmente Felipe Herrera, Reflexiones Generales accrca del Banco Interamericano, en Una Década de Lucha por América Latina, 1970.

10Aunque en determinado monento ambos desarrollos parecen converger como ocurre con la proposición formulada por Fidel Castro en la segunda sesión del Comité de los 21 en el sentido de que los Estados Unidos suministrara 30 mil millones de dólares durante un periodo de 10 años para el financiamiento del desarrollo de América Latina, estas dos líneas de evolución posteriormente se separan. Después de Buenos Aires, Fidel Castro no volverá a aparecer en ningún foro interamericano. 
Estas características explican a la luz de la manera cómo se originó el programa de la Alianza para el Progreso. Inicialmente dos grupos intervinieron en su gestación. El primero estaba integrado por un distinguido conjunto de personalidades $y$ académicos norteamericanos, reunidos por Adolf Berle a petición del presiclente Kennedy, entre los cuales se incluian hombres de orientación "liberal" en el mejori sentido de la palabra como Lincoln Gordon, Robert Alexander y Arthur Whitaker. El otro estaba compuesto por los colaboradores cercanos del gobernador de Puerto Rico, Luis Muñoz Marín, con quien Berle mantenía contacto descle hacía muchos años, y entre los cuales se contaban Arturo Morales Carrién y Teodoro Moscoso. El discurso en que el presidente Kennedy lanzó la Alianza para el -Progreso, el 13 de marzo de 1961, se apoyó tanto en las ideas contenidas en el informe preparado por esta fuerza de trabajo como en aquéllas propuestas por un grupo de nueve eminentes personalidades latinoamericanas convocadas con este objeto por José Antonio Mayobre, entonces embajador de Venezuela en los Estados Unidos, respondiendo a un llamado del propio presidente Kennedy. Este último grupo incluía a los directivos de los principales organismos regionales, como Raúl Prebisch, secretario ejecutivo de CEPAL; Felipe Herrera, presidente del BID; y Jorge Sol Castellanos, secretario ejècutivo del CIES.

Lo que importa destacar es que estos grupos, de alguna manera, interpretaban las principales corrientes democráticas y progresistas que por aquel entonces influían en forma más activa en la política de sus países, ya sea descle el gobierno o la oposición, y a sus principales líderes, como Rómulo Betancourt, Alberto Lleras Camargo, José Figueres, Víctor Raúl Haya de la Torre o Eduardo Frei Montalva.

La Alianza para el Progreso pudo incorporar así la mayor parte de los postulados que habían sido elaborados, y por los cuales habían luchado, los grupos más progresistas de América Latina. La Alianza para el Progreso proponía una década de "máximo esfuerzo" para promover el desarrollo de los países latinoamericanos. Su plataforma reconocía la necesidad de imprimir nuevo impulso al proceso de industrialización y, en general, a la diversificación de las economías latinoamericanas; de transformar las estructuras rurales arcaicas de los países de la región mediante planes de reforma agraxia; de promover el desarrollo social mediante programas masivos de vivienda, salud y educación; de dar vigoroso impulso al desarrollo científico y tecnológico mediante la modernización de las universidades latinoamericanas y progxamas de asistencia técnica; de promoyer el establecimiento de sistemas nacionales de planificación que permitieran dar coherencia a las políticas de desarrollo de los países latino- 
americanos; de impulsar el proceso de integración económica de los países cle la región con el objeto de ensanchar sus mercados; de que los Estados Unidos cooperaran a los programas de estabilización de precios de los productos básicos latinoamericanos mediante el examen de los problemas existentes caso por caso; de lanzar un amplio programa de cooperación financiera, contemplánclose una contribución inicial de los Estados Unidos de 500 millones de dólares, a través de un Fondo Fiduciario de Progxeso Social, etc.

A los efectos de este trabajo, no interesa tanto hacer una evaluación de los resultados obtenidos a través de la Alianza para el Progreso, como plantearse la interrogante de si continúan vigentes las premisas en que esta operación se fundara. Estas premisas eran dos. Por una parte, la presencia de regímenes o movimientos políticos de orientación "reformistas", relativamente homogéneos, en un número significativo de países latinoamericanos. Por la otra, la existencia de una supuesta "armonía natural de intereses" entre los Estados Unidos y América Latina, evidenciada precisamente por el hecho de que la Alianza hubiera recogido la mayor parte de los postulados defendidos por los movimientos reformistas anteriormente mencionados.

El hecho es que a fines del decenio pasado estas premisas comienzan a perder vigencia $y$, con ello, a alterarse fundamentalmente el patrón que presidió las relaciones internacionales de los países de la región durante los veinticinco años precedentes, como consecuencia de la aparición de nuevos factores, tanto en el plano internacional, como en el regional y el interno. La revolución peruana de octubre de 1968 y la nueva política latinoamericana del Presidente Nixon dan la pauta de los cambios que habrían de producirse.

Ante todo debe mencionarse la presencia de factores de orden internacional. Durante el pasaclo decenio se asiste a la clisolución del mundo rígidamente bipolar que emergió de la Segunda Guerra Mundial y a la graclual conformación de un mundo policéntrico, estimulado por el conflicto chino-soviético que se desarrolla fundamentalmente en los primeros años de la década y por la consolidación del Japón y de Europa Occidental. La aparición de nuevos centros de poder en el juego de las grandes potencias introduce una mayor fluidez en el sistema internacional. Dos factores aclicionales fortalecen esa tendencia al comenzar la década de los setenta. La crisis monetaria internacional, y las medidas adoptadas por el secretario del Tesoro Connally en agosto de 1971, dieron origen a una suerte de nueva "doctrina Nixon" orientada a reconocer una "soliclaridad limitacla" dentro del campo occidental y a requerir de sus aliados una mayor participación en las responsabiliclades y costos involucrados en el mantenimiento del orden mundial. Esta doctrina, al obligar a los países occidentales a depencler en menor medida de los 
Estados Unidos y a valerse más por sí mismos, tendió a erosionar la solidaridad existente entre los países desarrollados con economía de mercado y a debilitar el prestigio de los Estados Unidos, tanto entre los paises industrializados como frente al Tercer Mundo. La ulterior crisis energética contribuyó a acelerar el reordenamiento de las relaciones entre los países industrializados y los países en desarrollo.

En cuanto a los países industrializados, no es casualidad que a poco de desencadenarse la crisis monetaria, el gobierno pro norteamericano de Fukuda haya sido sustituido por el de Tanaka, que preconiza una mayor libertad de maniobra para el Japón, ni que finalmente se haya ampliado la Comunidad Económica Europea dejando atrás por igual la resistencia de Francia y las vacilaciones del Reino Unido. En lo que respecta al Tercer Mundo, tampoco es casualidad que la India, el paradigma de los países no alineados, hay'a suscrito poco después un tratado de amistad con la Unión Soviética, y que el número de estos países haya engrosado substancialmente con la incorporación de un conjunto de naciones del sudeste asiático en 1972, y con un número apreciable de nuevos miembros u observadores latinoamericanos el siguiente año. La distensión de las relaciones entre las dos Europas y los Tratados de Berlín; la política exterior cada vez más indepencliente de Rumania y los pasos encaminados al levantamiento de las sanciones contra Cuba; la segregación de Bangla Desh, y la creación de un nuevo estado, pese al apoyo tradicional de los Estados Unidos (y al heterodoxo apoyo chino) a Pakistán, constituyen otros tantos indicadores de la nueva situación de fluidez internacional.

Otros indicadores, sin embargo, revelan tendencias contrapuestas, encaminadas a provocar una mayor integración de las economías industriales, alentada por la clistensión de las relaciones este-oeste y por verticalización de las relaciones económicas entre los países industrializados y sus zonas de influencia. Los países de América del Norte, Europa Occidental y Japón, con una quinta parte de la población del mundo, generan los dos tercios de la producción mundial de bienes y servicios. El comercio entre ellos crece más rápidamente que el comercio mundial. La inversión extranjera, en gran parte norteamericana, tiende asimismo a concentrarse en ellos. Dentro de este grupo, los Estados Unidos continúan teniendo una posición predominante, y junto con la Unión Soviética parecen estar mejor preparados que el resto de los países industrializados para resistir los efectos de la crisis energética. Pero aun tomando en consideración estas calificaciones, es preciso reconocer una tendencia hacia una mayor fluidez en las relaciones internacionales, que abre nuevas perspectivas al Tercer Mundo, en general, y a América Latina en particular.

En el cambio experimentado por las relaciones internacionales de 
América Latina están operando también factores de orden regional. Ýa se ha hecho referencia al cuestionamiento de la hipótesis de la "armonía natural de intereses" que inspiró la formación del sistema interamericano y, en forma muy particular, la Alianza para el Progreso. Con la expropiación de la IPG, como acto inauguṛal y símbolo de la orientación que adoptaría la revolución peruana, se inicia una serie de procesos de imprevisible duración que, con habilidad varia, no tienen temor de plantear sus intereses frente a los Estados Unidos en el plano de la confrontación. De otra parte, se observa la emergencia $y^{\prime}$ consolidación de nuevas prácticas de consulta $y^{\prime}$ negociación conjunta entre los países latinoamericanos, manifestadas principalmente en la creación y el funcionamiento de la CECLA, y documentadas originalmente en el Consenso de Viña del Mar.

Por último, hacen su aparición factores de orden nacional. Se observa por esa época una ruptura de la relativa homogeneidad que existiera entre los sistemas políticos de los países latinoamericanos a comienzos del decenio de 1960 y la aparición de una diversidad de "caminos del desarrollo". Puede advertirse, sin embargo, un común denominador dentro de esa diversidad, caracterizado por el ensanchamiento de las bases de sustentación de los regímenes políticos en un número creciente de países, y'a sea como el resultado de procesos electorales o de otro tipo de experiencias. Cabe advertir que la tendencia hacia una mayor participación popular en los gobiernos de países en vías de desarrollo parece ser paralela a la propensión de esos gobiernos a asumir un mayor control sobre las relaciones exteriores de sus respectivas naciones.

Esta nueva constelación de circunstancias tenían que dar lugar a un cambio importante en el modo de inserción de América Latina en el contexto mundial. Hasta qué punto estos cambios facilitarán la formación de un subsistema regional en esta parte del mundo, que permita a sus países miembros mejorar su participación en el sistema internacional, es la pregunta que se intenta plantear en este trabajo.

3. ACENTUACIÓN DE LA PERCEPCIÓN DE AMÉRICA LATINA DE SU PROPIA IDENTIDAD EN EL CONTEXTO INTERNAGIONAL

La primera de las variables escogidas para examinar este proceso consiste en el grado de percepción que los países pertenecientes a una agrupación regional tienen de su identidad internacional. No estamos hablando aqui de la percepción que otros países tienen de la ho- 
mogeneidad de un conjunto de naciones que no tiene clara conciencia de sus vínculos de identidad. Tal podría ocurrir hoy con ciertas regiones de África o con los países marítimos del Asia Sucloriental. En el caso de América Latina, es indudable que ocurrió en el pasado, al menos en el siglo xviri cuando la reforma del pacto colonial acentuó las relaciones directas entre las colonias y la metrópoli y desarticuló los nexos incipientes que existían en el interior de la economía colonial, o en el siglo pasado cuando las potencias europeas miraban hacia Latinoamérica como un área de expansión sin que estos países percibieran un campo de intereses comunes ni una posibilidad de articulación.

La toma de conciencia de los países que constituyen una agxupación regional acerca de su identidad internacional -al igual que lo que ocurrió a lo largo del prolongado proceso de consolidación del estado nacional- suele generarse en la respuesta a un desafío externo. Para las agrupaciones de países pertenecientes al Tercer Mundo este desafío está constituido por la asimetría de sus relaciones económicas, tecnológicas, militares y políticas con los países industrializados. En el caso de América Latina, estas asimetrías han tendido a manifestarse con especial relieve dentro del contexto hemisférico, constituyendo un telón de fondo para observar el avance de su propia percepción como grupo identificable en el contexto internacional. La acentuación de esta percepción se revela, por una parte, en el relativo debilitamiento que ha experimentado en los últimos años la relación especial de los países latinoamericanos con Ios Estados Unidos y, por la otra, en un proceso correlativo de diversificación de sus relaciones con otras regiones del mundo.

El telón de fondo de este proceso está constituido, pues, por la creciente marginalización de las economías periféricas con respecto a las potencias industriales. Dentro del proceso de multipolarización a que se ha hecho referencia, los problemas y' reivindicaciones de los países en desarrollo no solamente se mantienen, sino que en general se agudizan. El proceso de deterioro de los términos de intercambio, tan ampliamente analizado, no solamente continúa respondiendo a las mismas causas sino que, en el periodo más reciente, ha tenido que enfrentar factores que tienden a agravarlo.

En primer lugar, una proporción creciente del comercio internacional está constituido por manufacturas y se realiza entre los paises inclustrializados. Entre 1948 y 1970 la participación de los países industrializados en las exportaciones intrazonales se elevó de un $64 \%$ a un $77 \%$. Al mismo tiempo, la vinculación interna de las economías en desarrollo se redujo del $29 \%$ al $19 \%$ entre los mismos años. En términos globales, la participación de los países en desarrollo en el comercio mundial se redujo del $30 \%$ en $194 \mathrm{~S}$ al $17 \%$ en 1970, obser- 
vándose una caída proporcionalmente mayor en el caso de América Latina del $11 \%$ al $5 \%$, respectivamente. ${ }^{11}$

En segundo lugar, en los últimos decenios se ha asistido a la proliferación de regímenes preferenciales discriminatorios. La proporción del comercio mundial que se realiza en virtud de la cláusula de la nación más favorecida ha declinado constantemente en el último periodo y la participación de las importaciones preferenciales en el comercio mundial se ha elevado del $10 \%$ en 1955 al $24 \%$ en 1970. Debe recordarse que, antes de su ampliación, la Comunidad Económica Europea mantenía acuerclos preferenciales con veintiocho países, a los cuales después de la ampliación se agregaron veinte países y diecinueve territorios dependientes, que han quedado en condiciones de asociarse a la Comunidad. ${ }^{12}$

En tercer lugar, durante el último período las políticas comerciales de los países inclustrializados no sólo no han experimentado piogreso substanciales sino que, como consecuencia de las crisis monetaria y energética, han tendido a incorporar nuevas restricciones. Es así como en los últimos años no se han registrado avances en cuanto a convenios sobre productos primarios en que participen conjuntamente importadores y exportadores; tampoco se han reducido las restricciones impuestas al acceso de productos agropecuarios a los mercados de los países industrializados, ni se han reducido los subsidios otorgados a los productores por estas últimas naciones; tampoco se han atenuado las medidas adoptadas por los países industrializados que afectan desfavorablemente las exportaciones no tradicionales de los países en desariollo.

En cuarto lugar, tratándose de estos últimos productos, el sistema de preferencias generales ha tenido una aplicación limitada. Ante todo, no ha sido ratificado por los Estados Unidos, situạción que perjudica substancialmente a los países latinoamericanos, para los cuales éste constituye su principal mercado. Además, la GEE conservó un margen de preferencia mayor para sus países asociados, cuyo número. aumentó considerablemente después de la ampliación de : la Comunidad, como ya se ha indicado. Por último, el sistema excluye los denominados "productos sensibles" que, por contemplar las manufacturas livianas o tradicionales, constituyen el grueso del potencial exportador de los países en desarrollo, exclusión que se extiende a la mayor parte de los productos agrícolas elaborados.

Las mismas tendencias se advierten en la dirección regional y sectorial de la inversión privada extranjera, la cual tiende a concentrarse

I1Aníbal Pinto y Jan Kñakal, América Latina y el cambio en la Economia Mundial, 1973.

12CEPAL, América Latina y lla Estrategia Intermacional del Desarrollo: Primera. Evaluación Regional, 1973, Segunda Parte, págs. 4 y 5. 
en los países industrializados y en el sector manufacturero. En el caso de los Estados Unidos, la participación de los países industrializados en la inversión extranjera proveniente de ese pais aumentó del $48 \%$ en 1950 al $67 \%$ en 1968, con la correspondiente disminución de la participación de los países en desarrollo en la inversión externa norteamericana. ${ }^{13}$

Similares consideráciones podrían hacerse en lo que respecta al proceso de desarrollo científico y tecnológico que se encuentra aún más concentrado en los países industrializados $\mathrm{y}$, muy en particular, en las empresas transnacionales. Lo anterior se advierte en la abrumadora diferencia entre la relación existentes en el esfuerzo interno de "investigación $y$ desarrollo" y el de importación de tecnología, entre los países industrializados y los paises en desarrollo. En efecto, tratándose de los primeros, la relación entre ambos términos es de entre 20 y 7 reces a una, en tanto que, en el caso particular de los países latinoamericanos esta relación presenta un signo inverso: 0,6 a $1,2 .{ }^{14}$

No hay dudas de que este proceso de marginalización de las economías periféricas" actúa como el "desafío externo" que faltaba para estimular la toma de conciencia de los paises latinoamericanos acerca de la identidad de sus problemas y objetivos en el cuadro internacional.

La primera manifestación de esta toma de conciencia es el relativo clebilitamiento de la relación especial de América Latina con los Estados Unidos. Ya se ha señalado como, al finalizar la Segunda Guerra Mundial, América Latina quedó adscripta a la esfera de seguridad de los Estados Unidos. Este fenómeno es paralelo a una pérdida de interés de los países europeos en los asuntos del área. Por una parte, la amenaza de un cataclismo nuclear de corta duración tendía a hacer olvidar las consideraciones geopolíticas que en el pasado habían valorizado la posición de América Latina como reservoir demográfico, fuente de aprovisionamientos $y$ materias primas $y$ punto de apoyo para las líneas de comunicación de las grandes potencias. Por otra parte, la posición de liderazgo conque los Estados Unidos emergen de la guerra inducen a sus aliados a delegar en ellos el mantenimiento de la alineación $y^{\prime}$ la seguridad de los países latinoamericanos durante la época de la guerra fría. EI hecho de que la crisis de los misiles cubanos, en 1962, haya sido resuelta unilateralmente por los Estados Unidos sin consuita de ninguna especie con sus aliados atlánticos, y la total carencia de resultados de los

${ }^{13}$ Anibal Pinto, Jan Kñakal, op. cit., pág. 45.

${ }_{14}$ Máximo Halty Carrere, El Desarrollo Tecnológico Zonal y la Transferencia de Tecnollogia. Documento de la Secretaria de la ALALG, Sec/PA 21, 1973, págs. $14,15$. 
gestos de acercamiento hacia América Latina realizados por algunos países europeos al promediar la década de 1960 (viaje del presidente De Gaulle por América Latina y política triangular del presidente Saragat y del primer ministro Fanfani) evidencian claramente el alejamiento deliberado de los países europeos durante todo el período.

Sin embargo, era inevitable que el desarrollo del détente durante los años sesenta tarde o temprano llevaría a reconsiderar estas actitucles. Así, hacia el final del decenio, los países europeos comenzarían a apreciar las ventajas económicas de corto plazo que podría depararles una mayor presencia en América Latina en lugar de supeditarlas a los objetivos de seguriclad planteados a largo plazo en los comienzos de la guerra fría. Por su parte, los Estados Unidos tenderían necesariamente a atribuir menos importancia a una declinación de su posición relativa en América Latina que a determinar qué países habrían de ocupar el terreno abandonado por ellos. Estas nuevas percepciones, provenientes de la distension, creaban una atmósfera propicia para un aflojamiento relativo de las relaciones hemisféricas.

Dentro de esta atmósfera se formuló la política latinoamericana del presidente Nixon, que se ha clado en llamar de "low profile" o "benign neglect" hacia América Latina, empleando en este último caso una expresión peyorativa.

Las razones de este cambio fueron analizadas en un documento presentado al Consejo de Relaciones Exteriores de los Estados Uniclos por el señor John N. Plank, quien actuó primeramente en la Brookings Institution y con posterioridad en la Universidad de Connecticut, en algunos de cuyos pasajes señalaba:

"Estoy completamente convenciclo de que una excesiva preocupación por la seguridad por parte de Estados Unidos ha dañado seriamente las relaciones Estados Unidos-América Latina, llevando al estado actual de nuestras relaciones: insatisfactorio, frustrante, lastimero... Ha sido públicamente registrado que el doctor Kissingex declara que el mundo actual es militarmente bipolar y políticamente multipolar. Greo que piensa que los desafíos estratégicos más serios para los Estados Unidos provienen, directa o indirectamente, de la Unión Soviética y no de un país latinoamericano. Pienso que ha descontado la significación del abandono ideológico en América Latina del 'american way' y que ha persuadiclo al Presiclente de que no se debe permitir que la protección de los intereses privados de Estados Unidos en América Latina asuma una abrumadora prioriclad... América Latina no es, en el análisis final, de una importancia de vida o muerte para los Estados Unidos, ya sea 
estratégica, política, económica o ideológicamente. América Latina puede valer una misa pero no vale una dedicación masiva de recursos económicos, energía política o atención militar. Por sí misma, América Latina no puede ir a ninguna parte -es un lugar 'estratégicamente solitario'; y si comienza a ix a alguna parte bajo las directivas de alguna otra gran potencia (Ia URSS), entonces Estados Unidos tratará con esa otra gran potencia, no con América Latina." 15

Una versión oficial de esa política se encuentra en un artículo firmado por Charles Meyer, subsecretario para asuntos interamericanos, quien usa el término acuñado por el propio presidente de los Estados Unidos al calificarla de una "asociación madura". Según el secretario de estado, "los Estados Unidos están buscando un nuevo equilibrio en sus relaciones con América Latina, mediante el aflojamiento de la antigua rienda paternal sobre las demás naciones del hemisferio... La política del presidente Nixon involucra el reconocimiento de que cabe esperar diferencias de prioridades e intereses, si bien con un espíritu de negociación y no de enfrentamiento esas diferencias pueden superarse."16

Se ha expresado la preocupación de que una política de "escaso relieve" por parte del gobierno de los Estados Unidos deje entregadas las relaciones con América Latina en manos de los intereses privados de ese país, respaldados por los sentimientos nacionalistas que expresa con frecuencia el Congreso ${ }^{17}$. Como quiera que los Estados Unidos deben velar necesariamente por los intereses de los ciudadanos en el exterior, a través de una especie de círculo vicioso, esta política conduciría a nuevas y más antipáticas formas de intervención por parte de los Estados Unidos, como ocurriría en el caso de nuevas expropiaciones de intereses norteamericanos en el área. Sin embargo, otras indicaciones parecen conducir a la conclusión opuesta. En realidad no está nada claro que ésta sea la perspectiva más probable y, en todo caso, no parece ser el propósito de la política latinoamericana de la actual administración estadounidense. En la declaración oficial formulada sobre esta materia en 1972, el presidente Nixon sostiene que "si una firma norteamericana fuera expropiada sin adoptarse medidas adecuadas para otorgar una compensación pronta, adecuada

$15 C i t a d o$ en A. Pinto, Relaciones Económicas entre América Latina y Estados Unidos: Implicaciones y Perspectivas Pollticas. En Estudios Internacionales, No 22, abril-junio, 1973.

16Charles Meyer, U.S. Policy toward Latin-America: Were We Stand Today. Department of State Bulletin, 15 de noviembre, 1971.

17Ver Luigi R. Einaudi, Latin America's development and the United States. En la recopilación del mismo autor, Beyond Cuba: Latin America Takes charge of its Future, 1974, pág. 222. 
y efectiva, existe la presunción de que el país expropiador no recibirá nuevos beneficios económicos bilaterales, a menos que factores importantes que afecten nuestros intereses requieran que actuemos de otra manera"1s. De hecho, los Estaclos Uniclos están en vías cle solucionar los conflictos pendientes en relación con la expropiación de la IPC en el Perú, y' a lo menos procuraron adoptar una posición ambigua en el caso cle los minerales del cobre en Chile ${ }^{40}$. Es eviclente, por otra parte, que caulquier intervención en defensa de determinados intereses en el área podría comprometer las inversiones de otras compañías, interferir con las relaciones comerciales entre los dos países u obstruir el acceso a ciertas materias primas. Estas consideraciones permiten anticipar que, probablemente, los Estados Unidos busquen en forma coherente una reducción de su presencia en el área.

Esta política, por lo demás, coincide con las tendencias que advierten en la evolución de las relaciones económicas entre los Estados Unidos y los países latinoamericanos.

Entre 1950 y 1970 la participación de las exportaciones latinoamericanas en el mercado de los Estados Unidos descendió del $24 \%$ al $11 \%$, en tanto que la participación del mercado latinoamericano en las exportaciones estadounidenses declinó en menor medida, pasando del $17,4 \%$ al $13,3 \%$ entre esos mismos años. Por su parte, la importancia del mercado norteamericano para las exportaciones de Latinoamérica se redujo aproximadamente del $60 \%$ al $40 \%$ en el período. El crecimiento más lento de las exportaciones latinoamericanas hacia los Estados Unidos, en comparación con sus exportaciones hacia otras regiones del mundo, se ve agravado por el hecho de que su estructura cambió poco en el último período: la participación de los productos primarios en las exportaciones latinoamericanas a los Estados Unidos sólo descendió del 95,6\% al 92,7\% entre el primer $y^{\prime}$ el segundo quinquenio de la década de los sesenta.

Tres hechos contribuyeron a este menor dinamismo de las relaciones comerciales entre estas dos partes del hemisferio. El primero es la falta de ratificación del sistema de preferencias generales por parte de los Estados Unidos. Un estudio publicado por la U.S. Tariff Commission en 1972 sobre un grupo de 160 productos manufacturados llega a la conclusión de que las importaciones procedentes de los países en desarrollo podrían pasar de 1.300 millones de dólares a 3.900 millones entre $1967 \mathrm{y}$ 1980, en caso que los Estados Unidos pusieran en vigor las preferencias, en tanto que en caso contrario,

18U. S. Foreign Policy for the 1970s: The emerging structure of Peace, a report to the Congress by Richard Nixon, 9 de febrero 1972, pág. 76.

19Paul Sigmund, The invisible blockade and thd overthrow of Allende, en Foreign Affairs, enero 1974. 
estas inportaciones sólo subirán de 1.300 a 2.300 millones en el período mencionado ${ }^{20}$. Atendida la importancia relativa que aún mantiene el mexcado de los Estados Unidos para las exportaciones latinoamericanas, puede apreciarse la significación que la entrada en vigor del sistema de preferencias generalizadas tendría paxa los países del área. En segundo lugar, como a continuación se señala, las inversiones norteamericanas han tendido a crecer en América Latina menos que en el resto del mundo. Como es sabido, existe una estrecha relación entre inversión y comercio. Un estudio realizado en el caso de las inversiones inglesas en Nigeria llega a la conclusión de que cada 100 libras esterlinas invertidas en este último país generan un comercio adicional de alrededor de 40 libras esterlinas. Es indudable que, de mantenerse la tendencia a una menor participación relativa de América Latina en las inversiones norteamexicanas, ello habrá de incidir en los flujos comerciales entre los países respectivos. En tercer lugar, es igualmente conocida la incidencia sobre el comercio de las "ataduras" de los fondos canalizados a través de los programas de ayuda externa. La proporción de la ayuda suministrada a través de la AID en condiciones atadas aumentó del $41 \%$ al $98 \%$ entre 1960 y 1968. Desde hace algunos años existen fuertes presiones para revertir esta tendencia, proceso que se inició con el anuncio efectuado durante el mensaje dirigido por el presidente Nixon a la Sociedad Interamericana de la Prensa, en octubre de 1969, en el sentido de que los fondos proporcionados por los Estados Unidos podxían sex utilizados libremente dentro de la región.

Finalmente, hay que señalar que la participación de América Latina en la inversión extranjera directa de los Estados Unidos entre 1950 y 1968 , descendió del $38 \%$ al $16 \%$.

Es natural que esta menor presencia de los Estados Unidos en el área haya sido acompañada por una cierta diversificación de las relaciones de América Latina con la Comunidad Económica Europea, el Japón, el campo socialista y el Tercer Mundo. En vísperas de la Segunda Guerra Mundial, tres países concentraban las dos terceras partes del comercio exterior latinoamericano, a saber, los Estados Unidos, Alemania y el Reino Unido. En 1970, esa proporción era ocupada por siete países. Las relaciones comerciales entre América Latina y la CEE, sin perjuicio de las mayores restricciones impuestas por ésta en el último período, crecieron a un ritmo promedio anual del $6,2 \%$ durante el pasado decenio en comparación con una tasa del $3,5 \%$ en el caso de comercio entre América Latina y los Estados Unidos. Debe recordarse que al presente la Europa de los Nueve

20U.S. Tariff Commission: Probable effect of tariff preference for developing countries, 1972, citado en CEPAL, América Latina $y$ la Estrategia Internacional de Desarrollo, Primera Evaluación Regional, 1973, Segunda Parte, pág. 13. 
representa un mercado comparable al de los Estaclos Undios para las exportaciones latinoamericanas, con una participación del $27 \%$ y el $29 \%$, respectivamente. En caso de persistir las tasas de crecimiento anteriormente mencionadas, la CEE sustituiría, en el plazo de unos pocos años, a los Estados Unidos como el principal mercado para las exportaciones de la región. Los países latinoamericanos han venido luchando desde fines del decenio pasado para atenuar los efectos desfavorables de las regulaciones comunitarias sobre sus exportaciones y para conseguir la adopción cle medidas de cooperación en los campos comercial y económico entre las dos regiones. Estos esfuerzos dieron Iugar, particularmente a partir de la VI Reunión Extraordinaria a nivel ministerial de CECLA, en julio de 1970, al establecimiento de mecanismos permanentes de consulta y cooperación entre ambas partes.

Aunque en cifras absolutas las relaciones comerciales entre América Latina y el Japón son aún modestas, su ritmo de crecimiento es extraordinariamente dinámico. Durante el decenio pasado las exportaciones latinoamericanas a dicho país aumentaron a un ritmo de un trece por ciento anual y la participación del Japón en las exportaciones de la región se elevó, de esta manera, del $4 \%$ en el primer quinquenio al $6 \%$ en el segundo. Este clinamismo se desató en una de las áreas más promisorias para el desarrollo de las relaciones económicas internacionales de América Latina. Dichas perspectivas se ven reforzadas por el rápido crecimiento de la participación del Japón en el comercio mundial así como por los niveles y modalidades del desarrollo tecnológico alcanzado por ese país. En 1971, los países del Acuerdo de Cartagena establecieron una Comisión Conjunta Andinojaponesa, a nivel gubexnamental, precedida de una declaración en que se instaba a estudiar asuntos de interés común y a llegar a acuerdo en relación con dichas materias. Más adelante, en la XIV Reunión de la GEGLA a nivel de expertos, celebrada en setiembre de 1972, se formuló una Declaración sobre Relaciones entre América Latina y el Japón, que podría servir de antecedente para el establecimiento de un mecanismo de consulta de carácter permanente.

El comercio de América Latina con los países socialistas, durante la década de 1960, se concentró fundamentalmente en Argentina y Brasil y acusó cierto crecimiento, si bien experimentó pronunciadas fluctuaciones. En cuanto a los dos países mencionados, es interesante destacar que el comercio de Argentina con la Unión Soviética pasó de 61 millones de dólares en 1960 a 76 millones en 1970, mientras que el del Bxasil aumentó de 71 millones en el primero de estos años a 135 millones en el último. También es interesante destacar que el país que ocupó el tercer lugar en su comercio con la Unión 
Soviética, en 1970, fue Colombia con 37 millones de dólares, en circunstancias de que estas relaciones habian sido prácticamente inexistentes durante el primer quinquenio. Lo anterior conduce a la hipótesis cle que no existiría una correlación entre el mayor o menor grado cle pluralismo ideológico, por una parte, y del grado de cliversificación de las relaciones internacionales, por la otra. Se advertiría, en cambio, una vinculación entre (a) el grado de diversificación de las economías respectivas, (b) la participación de productos no tradicionales en sus exportaciones y (c) el grado de diversificación de sus relaciones exteriores. Parece claro también que, así como Europa Occidental y el Japón desempeñaron un papel importante en la década de los sesenta al suministrar a América Latina nuevas alternativas en adición a sus relaciones con los Estados Unidos, la Unión Soviética y China jugarán un papel similar en la década del setenta debido a su rol de gran potencia y a su creciente interés en obtener may'ores beneficios en la división internacional del trabajo. Por otra parte, atendido el tamaño de esos mercados, puede predecirse que incluso una modesta incursión de América Latina en ellos podría implicar cambios profundos en el patrón tradicional de sus relaciones económicas y comerciales. ${ }^{21}$

Por último, la necesidad de negociar con economías centralmente planificadas o empresas públicas se ha prestado a opiniones contradictorias. Por una parte, se ha señalado que los paises latinoamericanos exportan productos primarios, cuya tipificación internacional es simple y ampliamente conocida, e importan manufacturas, bienes de capital e intermedios, con especificaciones técnicas complejas que, cuando provienen de países socialistas, suelen diferir de aquellas que requiere la estructura industrial de los países latinoamericanos. Se agrega que, aunque estas diferencias no fuesen tan grandes, el desconocimiento acerca de tales especificaciones así como de las instituciones que intervienen en el manejo de las relaciones comerciales respectivas, constituyen obstáculos adicionales al comercio entre ambas regio$n^{22}{ }^{22}$. Sin embargo, desde otro ángulo, se ha señalado que países en que el sector público generalmente tiene una gravitación importante en la economía, como es el caso de los países en desarrollo, pueden tener mayor facilidad para negociar con economías centralizadas o con gobiernos dirigistas dentro del campo occidental, y en especial con empresas públicas. Así, por ejemplo, a fines del decenio pasado la empresa estatal Renault ganó una licitación para establecer una planta ensambladora de automotrices en Colombia. Los licitantes derrotados - la Ford, General Motors y Chrysler- con-

21Herbert Goldhammer: The non hemisferic powers in Latin America, en Luigi

R. Einaudi, op. cit., págs. 180 y 181.

22CEPAL, op. cit., pág. 66. 
sideraron insensato que el ganador se comprometiera a comprar y comercializar productos colombianos - tan diferentes como café y tabaco, carne y' arroz- por un valor equivalente al de las autopiezas importadas en Francia o en el exterior. Sin embargo, una empresa estatal como la Renault, no tenía dificultacles aparentes para hacerlo. ${ }^{23}$

Finalmente, en esta misma línea, se puede clestacar que en el último período ha aumentado la participación latinoamericana en el grupo cle los países no alineados. En la Conferencia de Argel, de 1973, participaron delegaciones de Argentina, Chile, Cuba, Guyana, Jamaica, Perú y Trinidad y Tobago, y asistieron como observadores: Barbados, Bolivia, Brasil, Colombia, Ecuador, Mréxico, Panamá, Uruguay y Venezuela. En abril del mismo año, se celebró en Santiago de Chile una Reunón de Cientistas Sociales del Tercer Mundo convocada por las Comisiones Regionales de las Naciones Unidas, en donde se aprobó la creación de un llamado Thir d World Forum, destinado a "expresar opinión acerca de los problemas internacionales que afectan al Tercer MIundo en sus relaciones con el mundo desarrollado". Aún están por determinarse Ias diferencias y afinidades existentes entre los países latinoamericanos y las naciones en desarrollo asiáticas y africanas.

4. COHERENGIA Y COORDINAGIÓN DE LAS POLÍTICAS EXTERIORES DE LOS PAÍSES DE LA REGIÓN

La segunda de las rariables rutilizadas en este trabajo para apreciar las tendencias favorables o adversas a la formación de un subsistema regional latinoamericano se refiere al grado de coherencia y coordinación de las políticas exteriores de los países participantes. Es necesario insistir en los dos conceptos involucrados en la enunciación precedente -coherencia y' coordinación- pues no son equivalentes y no siempre se verifican al mismo tiempo en la práctica. En efecto, es posible que un conjunto de países persigan los mismos objetivos a través de políticas similares sin que medie coordinación entre ellos. El caso de los países exportatlores de petróleo proporciona un buen ejemplo al respecto. Es evidente que sus objetivos fueron los mismos antes y después de la OPEP. La coordinación de sus políticas y de sus acciones concretas a partir del establecimiento de dicha organización, significó una gran diferencia, $\mathrm{y}$ condujo a resultados

23Herbert Goldhammex, op. cit., pág. 176. Ver también Goldhammer: The Foreign Powers in Latin America, 1972, págs. $36 \mathrm{y} 37$. 
que no se habrían podido lograx mediante la simple coherencia de los objetivos perseguidos. La coherencia y coordinación de las políticas exteriores de los paises pertenecientes a una agrupación regional es lo que permite hablar de runa "politica internacional" en el plano de las regiones.

En el caso de América Latina, las tendencias ya apuntadas hacia el fortalecimiento de los mecanismos de consulta y coordinación entre los paises latinoamericanos parece estar dando lugar a una suerte de "política regional latinoamericana" aún embrionaria, caracterizada por un conjunto de objetivos comunes y formulada en diversos escenarios sobre los cuales los países latinoamericanos procuran ganar cada vez mayor control.

Entre los principales eventos que han permitido avanzar hacia la formulación de esta política regional, en el período más reciente, cabe señalar las últimas reuniones de cancilleres latinoamericanos entre sí o con la participación del secretario de estado de los Estados Unidos, en lo que ha dado en llamarse "nuevo diálogo" entre éstos y América Latina; los trabajos encaminados a la reforma de la OEA, que han tenido lugar entre la celebración de las dos últimas Asambleas Generales, particularmente los desarrollados por la Comisión Especial que se reunió en Lima y en Washington con el encargo de estudiar el sistema interamericano y de proponer medidas para su reestructuración; las dos últimas conferencias del CIES, celebradas en Bogotá y en Quito, respectivamente; los trabajos del CECON; las últimas reuniones de la CECLA, convocadas ex profeso para analizar problemas de actualidad, de carácter específico; el XV Periodo de Sesiones de la CEPAL, desarrollado en Quito en marzo de 1973, en que este organismo celebró sus veinticinco años de existencia y se aprobó un informe a nivel gubernamental; la Reunión de Comandantes en Jefe de las Fuedzas Armadas Latinoamericanas, celebrada en Caracas, en agosto de 1973; la Conferencia de Argel, de países no alineados, en que América Latina turo una actuación más destacada que en las reuniones anteriores de este grupo de países; la Reunión Extraordinaria del Consejo de Seguridad de las Naciones Unidas, celebrada en Panamá, en marzo de 1973; la participación concertada de los países latinoamericanos en otras conferencias especializadas de las Naciones Unidas, como la VI Sesión Extraordinaria de la Asamblea Genexal, que se realizó en Nueva York en abril de 1974, en torno al problema de los productos básicos, o la Conferencia sobre el Derecho del Mar programada en Caracas a partir de junio del mismo año, etc.

A través de estos eventos, los países latinoamericanos han iclo dando cuerpo al propósito de adquirir mayor presencia en el escenario internacional o de estructurar foros propios para plantear sus 
problemas y elaborar soluciones a la vez que, gradualmente, han ido elaborando lo que podría ser la plataforma de una política internacional de alcance regional.

En el primero de estos aspectos, los esfuerzos más importantes son, sin duda, los que se refieren a la reestructuración del sistema interamericano. Pero ellos no se limitan a la reforma de la OEA, en tomo a cuya necesidad parece existir consenso, sino que se han extendido a mociones encaminadas a la revisión del TIAR y a la adecuación del BID a las necesidades actuales de los países de la región. Por momentos, estos esfuerzos parecen verse sobrepasados por el desarrollo del "nuevo diálogo" entablado entre los cancilleres de los Estados Unidos $y^{\prime}$ de los países situados al sur del hemisferio.

El movimiento tendiente a la reforma de la OEA se inició en la tercera Asamblea General de la Organización, celebrada en la ciudad de Washington, en abril de 1973. En esa oportunidad se esbozaron tres posiciones que, a grandes rasgos $y^{\prime}$ no obstante ciertos cambios experimentados en las posiciones de algunos países, se han mantenido hasta ahora. Algunos países, como los Estados Unidos, Brasil, Bolivia, Paraguay y otros, sostuvieron la posibilidad de perfeccionar el actual sistema. De acuerdo con la exposición efectuada por el secretario general de la OEA en esa oportunidad, la Carta de la Organización "es suficiente para permitir cambios fundamentales que hagan posible adaptar la institución a las realidades de nuestro tiempo". Agregaba Galo Plaza que lo que "falta en el diálogo entre Estados Unidos y' Latinoamérica es un espíritu más fuerte de soliclaridad y un más claro reconocimiento cle los intereses comunes o convergentes". Como una manera de remozar la Organización, el secretario general proponía que se fijaran "los nuevos campos de atención de la OEA -conservación del medio, rápido crecimiento demográfico, el desempleo- que no fueron abordados en la Carta". Una segunda posición, no del todo coherente, fue presentada por países como Perú, Chile, Barbados, Panamá. El entonces canciller de Chile expuso una posición que, siendo la más articulada exa tal vez la menos realista, al proponer la institucionalización de los dos polos que constituían el sistema hemisférico - América Latina y los Estados Unidos- la latinoamericanización del CIAP y del CACTAL, con respecto a la OEA, y de la CEPAL; el levantamiento de las sanciones a Cuba, y la revisión del TIAR. La que parece prevalecer es una tercera posición, en la que han ido convergiendo Argentina, Costa Rica, Ecuador, México, Venezuela y otros países, encaminada al reconocimiento del pluralismo ideológico en el continente, a la incorporación de los restantes países del hemisferio a la OEA y el fortalecimiento del papel de los países latinoamericanos en el seno de la Organización. El Perú propuso la creación de una comisión 
especial encargada de estudiar la reorganización de la OEA. La comisión fue creada, celebrando tres períodos de sesiones durante 1973, en el curso cle los cuales pudo pasarse revista a un cúmulo de antecedentes que se pusieron a disposición de los cancilleres del hemis. ferio reunidos en la IV Asamblea General, celebrada en Atlanta, en abril de 1974.

Estas preocupaciones, vinculadas a la reforma de la OEA, se han extendido a otros organismos o instrumentos pertenecientes al sistema interamericano.

Ante todo, se extendieron al ámbito del Banco Interamexicano de Desarrollo. En la XXV Reunión de la Asamblea de Gobernadores de la Institución, celebrada en Santiago de Chile en abril de 1974, la delegación venezolana tuvo un papel destacado al anunciar el propósito del gobierno de ese país de canalizar una parte de los recursos adicionales provenientes de sus exportaciones petroleras a apoyar los esfuexzos de desarrollo de los países latinoamericanos -particularmente de aquellos que han alcanzado un menor grado de desenvolvimiento económico- mediante una variedad de medidas que incluyeron la proposición de establecer un fondo fiduciario administrado multilateralmente por el Banco Interamericano, de acuerdo con reglas propias, y abierto a las contribuciones que deseen efectuax los países latinoamericanos que poseen mayores recursos. Dentro de este contexto, el gobernador por Venezuela señaló que "Ia misma coyuntura internacional, la situación del Banco, y las nuevas perspectiras que se abren al desarrollo de la América Latina nos obligan a formular algunas consideraciones sobre la necesidad vital de la transformación del Banco Interamericano de Desarrollo en un banco latinoamericano que vincule en calidad de iguales a la América Latina con Ios países industrializados miembros del Banco". A este respecto, agregó:

"La Iatinoamericanización del Banco no implica desconocer el papel fundamental que ha desempeñado EE.UU. en el fortalecimiento del Banco. Responde si, a la convicción de que ha llegado el momento de convertir a la institución en un organismo cuya estructura financiera y organización administrativa refleje, primordialmente, los intereses de América Latina.

En opinión de Venezuela, el aspecto crucial con relación a la latinoamericanización del Banco, radica en la necesidad imperiosa de que, a la brevedad posible, los países de América Latina obtengan una participación mayor en el capital ordinario del Banco o que se modifique el Convenio Constitutivo en forma tal que las decisiones fundamentales del Directorio correspondan a los intereses básicos del desarrollo de la América Latina. 
Esta mayor participación en el capital ordinario del Banco, no contradice en ningún caso la participación y colaboración de los socios extracontinentales ni el mantenimiento de la transferencia de recursos en la región por parte de EE.UU., dentro del marco de su traclición de solidaridad continental. Para alcanzar esta meta, proponemos que los países de mayor desarrollo de la región le presten los recursos a aquellos que todaría están en una fase de menor desarrollo."24

En otro orden de cosas, en la Conferencia de Comandantes en Jefe de las Fuerzas Armadas de países latinoamericanos celebrada en Caracas en agosto de 1973, se inició una interesante evolución hacia la acuñación del concepto de "seguridad económica colectiva". Este se basa en la percepción de la interclependencia existente entre seguridad y desarrollo y, por lo tanto, en la convicción de que cualquier sistema de seguridad a nivel continental deberá ir acompañado de una acción decidida en apoyo del progreso de los pueblos del hemisferio, en cuyas condiciones de subdesarrollo se originan precisamente las principales amenazas para la paz hemisférica. El nuevo concepto implica tambien reconocer que cualquier medida de coherción económica, proveniente del exterior, constituye una amenaza para la seguridad de la región. Resulta interesante recordar que en 1947, cuando en Río de Janeiro se cliscutía lo que iba a ser el Tratado Interamericano de Asistencia Recíproca, Guba propuso que se incluyera una disposición prohibiendo "las amenazas y agresiones de carácter económico" 2s. Aunque en la Reunión de Caracas la tesis, planteada por Argentina y Perú, solamente fue apoyada por Colombia, Ecuador, Panamá y Venezuela, no cabe dudas de que el hecho abre interesantes perspectivas. Refiriéndose a esta tesis, el general Edgardo Mercado Jarrin posteriormente expresó:

"En principio, para nosotros, el concepto de seguridad continental que se funda en el supuesto de un ataque armado proveniente de ultramar, lo consideramos superado y opinamos en este sentido tras comprobar la notoria declinación de la situación de tensión que antes ha imperado en el mundo. Por lo tanto, al no existir ya ese tipo de amenaza, nuestra seguridad en el ámbito multinacional, vale decir nuestra seguridad colectiva, debería fundarse en consideraciones de orden interno que

24Discurso del gobernador por Venezuela, Ministro de Hacienda señor Héctor Hurtado en la II Sesión Plenaria de la XV Reunión de la Asamblea de Gobernadores del BID. En el mismo sentido se ha formulado el Gobierno de la República Argentina.

25Ver Gordon Connall-Smith, op. cit,, pág. 151. 


\section{ESTUDIOS INTERNAGIONALES}

atañen a todos los países interesados en este problema. En este sentido, $y$ a la luz de la realidad latinoamericana, pensamos que un sistema de seguridad americano no puede ignorar que la causa de malestar y de amenaza para la paz es el subdesarrollo y las medidas de coherción económica. De aquí que, a los antiguos planteamientos de seguridad colectiva basados en lo puramente militar y en la represión ideológica, nosotros oponemos una concepción amplia de seguridad cuyo fundamento sea garantizar el desarrollo de los pueblos."

Si se quisiera hacer un balance de las posiciones adoptadas por los distintos países frente a estas materias y pudiera ensayarse una prospectiva, ésta indicaría que por el momento el sistema interamericano continuará siendo un marco importante -seguramente el más importante- para la expresión de los intereses y el desarrollo de las relaciones exteriores de los países de la región, pero que dentro de ese marco tenderá a producirse una mayor polarización entre los países latinoamericanos y los Estados Unidos. Es necesario precisax que este concepto no es sinónimo de conflicto o confrontación. Los resultados con que concluyeron algunas de las reuniones más importantes celebradas recientemente en el ámbito hemisférico avalan esta conclusión.

EI informe final de la VIII Reunión del CIES a nivel ministerial, celebrada en Bogotá en los meses de enero y febrero de 1973, no contó con el acuerdo de la delegación norteamericana. Por su parte, la Evaluación de la Estrategia Internacional de Desarrollo, aprobada en el XV Periodo de Sesiones de la CEPAL que turo lugar en marzo de 1973 en Quito, contenía 92 párrafos de los cuales 51 fueron objetados por los Estados Unidos. También cabe recordar que en la reunión del Consejo de Seguridad de las Naciones Unidas celebrada en Panamá en marzo de 1973 Ios Estados Unidos hicieron uso por cuarta vez en la historia de las Naciones Unidas de su derecho de veto, para oponerse a la tesis de los miembros latinoamericanos sobre el Ganal de Panamá, posición que sin embargo fue modificada un año más tarde.

Un caso en que se evidenció la disparidad de voluntades entre las dos partes del hemisferio se encuentra en el funcionamiento de la Comisión Especial de Consulta y Negociación (CEGON), creado en 1970 como consecuencia del Consenso de Viña del Mar, dentro del marco de la OEA, con el mandato de identificar los obstáculos que se oponían al mejoramiento de las relaciones económicas entre América Latina $\mathrm{y}$ los Estados Unidos. Durante un primer periodo, el

26 General Edgardo Mercado Jarrin en entrevista exclusiva otorgada a La Opinión, de Buenos Aires, publicada en su edición del $1^{9}$ de setiembre de 1973. 
CECON realizó una labor eficaz en la identificación de estos problemas, si bien no pudo avanzar hacia la etapa de las negociaciones. En la VIII Reunión del CIES a nivel ministerial, celebrada en Bogotá en 1973, se adoptó una Resolución en la cual se manifiesta que el CECON no ha podido cumplir con los objetivos que habían siclo encomendados, particularmente en lo que se refiere a la promoción del acceso de productos de especial interés para América Latina en el mercado norteamericano, a lograr la reducción de las barreras comerciales que protegen a este último y a la aprobación de un reglamento para sus propias reuniones (Resolución 52/VIII/73).

Dentro de esta tendencia hacia una mayor polarización dentro del sistema interamericano, los países de América Latina han encontrado crecientemente una expresión en la GECLA, a partir de sus primeros resultados expresados en el Consenso de Viña del Mar. Este fue el marco utilizado por los países de la región para articular su posición frente a la crisis monetaria intermacional en una reunión celebrada en Buenos Aires, en setiembre de 1971. Durante 1973, la CECLA se convirtió en el principal foro para concertar las posiciones latinoamericanas frente a las negociaciones comerciales internacionales que constituirían la rueda Nixon. Del mismo modo, la CECLA ha desempeñado un papel muy importante en la orientación de las relaciones entre los países latinoamericanos y la Comunidad Económica Europea, lleganclo a proponer la creación de un Centro para la Expansión Comercial entre la CEE y América Latina. En el mismo sentido, la CECLA ha abordaclo el tema de las relaciones económicas entre América Latina y el Japón, particularmente la reunión celebrada en Santiago de Chile en setiembre de 1972, y ha estimulado la formulación de un programa de cooperación entre ambas partes.

Permítasenos ahora ocuparnos del segundo de los aspectos planteados al comienzo de esta sección, esto es, la configuración de una plataforma común en la cual tienclen a converger elementos importantes de la política exterior de los países latinoamericanos. No sería posible aquí $-\mathrm{y}^{\prime}$ no lo sería siquiera a través de esfuerzos mucho más importantes que el que representa este ensayo- proporcionar un cuadro medianamente completo de las concordancias y divergencias que presentan las políticas exteriores de los países de la región en el contexto internacional. Tampoco sería posible evaluar en estos momentos la solidez o precarieclad del consenso alcanzado en torno a ciertas materias. Se abre aqui, por consiguiente, un importante campo de investigación que nos limitaremos a señalar mediante runas cuantas generalizaciones.

A estos efectos, agruparemos algunas de las principales tesis y objetivos que tienden a configurar la plataforma en que se apoya 
esta incipiente "política exterior regional" de los países latinoamericanos, en los siguientes campos: (a) problemas relacionados con el control y aprovechamiento de los recursos naturales existentes en la región; (b) problemas vinculados al comercio exterior de los paises latinoamericanos y (c) problemas relacionados con el proceso de transferencia de recursos externos y la actuación de las corporaciones multinacionales. ${ }^{27}$

Durante los últimos años, un número creciente de gobiernos latinoamericanos han robustecido su roluntad de recuperar o acentuar su control sobre los recursos naturales existentes en sus territorios, lo que ha dado lugar a una nueva ola de expropiaciones y nacionalizaciones de diverso estilo. El caso más destacado, sin duda, fue la expropiación a fines de 1968 por parte de la Junta Militar Peruana, de los yacimientos e instalaciones de la Brea 7 Pariñas, de propiedad de la International Petroleum Company (IPG), el mayor monopolio petrolero del Perú que había venido siendo objeto de permanente crítica proveniente de los más diversos sectores nacionales. Como es sabido, a esta medida siguieron otras que terminaron con la expropiación de la totalidad de los bienes de dicha empresa en el Perú, y su expulsión del país. De esta manera, el caso de la IPC se convirtió en origen y símbolo de la revolución peruana. Al mismo tiempo, el gobierno militar de ese país iniciaba una reforma agraria que comenzaba por afectar los intereses extranjeros en el agro, particularmente los ingenios azucareros de la costa de propiedad norteamericana y las vastas explotaciones agrícolas y ganaderas de la Cerro de Pasco Corporation en la sierra. Sin embargo, estas tendencias comenzaxon tal vez con el proceso de "chilenización" del

27A1 agrupar de alguna manera los temas más relevantes que se presentan en este campo, es ineritable incurrir en algunas arbitrariedades, así como en coincidencias con clasificaciones ensayadas en otros trabajos. En los comentarios presentados por Richard Fagen al trabajo de Luigi Einaudi sobre La Politica Latinoamericana de los Estados Unidos en los años 70, durante la Conferencia sobre las Relaciones Políticas entre América Latina y Estados Unidos, organizada en 1972 por el Instituto de Estudios Peruanos y el Social Science Research Council, estos temas se clasifican en relativos a soberanía, inversión, comercio, ayuda y organismos internacionales. E1 hecho de que los problemas relativos a la ayuda no se traten en este ensayo, aparte de constituir una de las arbitrariedades mencionadas más arriba, revela la convicción del autor de que, por una parte, el interés que estos problemas despertaron a lo largo del pasado decenio decayó considerablemente durante los últimos años mientras que, por la otra, hoy en día la ayuda externa tiende a concebirse dentro de una visión más integrada del proceso de desarrollo, en general, y de las relaciones económicas internacionales, en particular. In cuanto a los organismos internacionales, éstos no constituyen tanto objetivos cuanto instrumentos de la política exterior de las naciones, por lo que las acciones emprendidas por los países latinoamericanos para adquirir mayor presencia en àlguno de ellos ya fueron reseñadas con referencia a los "escenarios" en que se desenvuelven sus políticas exteriores. 
cobre controlado por las compañías Anaconda y Kennecot durante el gobierno de Frei, seguido ulteriormente por la expropiación de los correspondientes yacimientos, aprobada por unanimidad por el congreso de Chile en 1971. Cabe xecordax también el conflicto planteado, a partir de 197l, entre el gobierno de Guyana y la corporación multinacional Alcan Aluminium Limited, que concluyó con la nacionalización de la Demerara Bauxite Company (DEMCBA). La legislación sobre hidrocarburos adoptada en los últimos años poiEcuador y, sobre todo, las declaraciones formuladas por el presidente venezolano Carlos Andrés Pérez anunciando la reversión anticipada de las concesiones petroleras, constituyen otros ejemplos de esta tendencia. No es casualidad que pocos meses después del asunto de la IPC Ios gobiernos latinoamericanos, reunidos por primera vez dentro del marco de CECLA, incluyeran en el Consenso de Viña del Mar el reconocimiento "del derecho soberano de cada país de disponer libremente de sus recursos naturales".

Un área en que los países latinoamericanos se han mostrado paiticularmente activos, en lo que se refiere al control de sus riquezas naturales, se relaciona a los recursos marinos. Ya sea a través de actos unilaterales o de diversos instrumentos colectivos, los países de la región han ido configurando lo que podría denominarse una doctrina latinoamericana sobre el derecho del mar, cuyo fundamento es de carácter preponderantemente económico-social. De acuerdo con esta concepción, los nexos existentes entre el territorio de un estado y el espacio marítimo adyacente confieren al estado ribereño un derecho preeminente a la explotación de los recursos naturales situados en dichos espacios y a fijar los límites de éste. Esta doctrina se ha traducido en que un número creciente de estados latinoamericanos ha reivindicado competencias especializadas, para la explotación preferente de los recursos naturales renovables y no renovables existentes en las aguas, lecho y subsuelo marítimos, hasta una distancia de 200 millas marinas. Esta doctrina no afecta el derecho de las comunicaciones ni los demás derechos reconocidos, más allá de las doce millas del mar texritorial, en el derecho clásico internacional. Se establece así una fórmula que obedece a la necesidad de compatibilizar los legítimos derechos de la cominidad internacional y de terceros países en materia de comunicaciones y. otras libertades, con los intereses económicos de los estados ribereños en cuanto a la conservación y explotación de los recursos naturales del mar adyacente en función de sus objetivos de desarrollo. Esta posición se complementa con el interés de los países latinoamericanos en el pleno mantenimiento del carácter internacional de los fondos marinos y oce?́nicos, así como de sus recursos y riquezas, de acuerdo con la. Resolución 27/49 (XXV) de la Asamblea General de las Naciones 
Unidas. En este interés se encuentra implícita la aspiración de que, para la administración de dicha zona se establezcan mecanismos multinacionales que aseguren una adecuada participación de todos los países del mundo en la explotación de dichos recursos ${ }^{28}$. Hasta la fecha, han adhericlo a la tesis de las 200 millas El Salvador (1950); Ghile, Ecuador y Perú (1952); Nicaragua (1965); Argentina (1966); Panamá (1967); Uruguay (1969), Brasil (1970) y Costa Rica (1972), debiendo recordarse que los paises latinoamericanos que suscribieron la Declaración de Santo Domingo ese mismo año, manifestaron su apoyo al reconocimiento, a través de un acuerdo mundial, de Ia facultad de los estados ribereños para extender sus jurisdicciones marítimas hasta las 200 millas $^{29}$. Los países latinoamericanos se han preparado activamente para participar en la Conferencia sobre el Derecho del Mar de Caracas, a partix de junio de 1974.

Un hecho destacado en este mismo sentido, y que podría dar lugar a un acontecimiento histórico, es el apoyo unánime prestado a $\mathrm{Pa}$ namá por los demás paises latinoamericanos durante la Conferencia realizada en ese país por el Consejo de Seguridad de las Naciones Unidas en cuanto a sus reivindicaciones sobre la zona del Canal. En la Conferencia preparatoria para el "nuero diálogo" celebrada en Bogotá, en noriembre de 1973, los cancilleres de América Latina y el Caribe acordaron incluir en la agenda de las conversaciones que habrían de mantener con el secretario de estado norteamericano, un punto relativo a la "solución de la cuestión del Canal de Panamá". Por su parte, antes de acudir a la Reunión de Tlatelolco en febrero de 1974, el secretario de estado Kissinger logró obtener una definición de su gobierno favorable a la tesis panameña.

Las tendencias manifestadas por los países latinoamericanos a asumir un mayor control sobre sus recursos naturales, deben tomar en cuenta el hecho de que las empresas multinacionales que generalmente actúan en tales sectores, constituyen corporaciones complejas, verticalmente integradas. Ello significa que, generalmente, la em-

is Chile, Kuvait y' Somalia presentaron en la UNCTAD III, un proyecto de Resolución en virtud del cual todos los estados que se ocupan de la extracción y aprovechamiento comercial de las materias primas obtenidas en las profundidades marinas internacionales, se comprometen a suspender dichas actividades mientras no se atcance un acuerdo sobre el sistema juridico internacional que regirá la explotación de esos recursos. En el Plenario de la UNCTAD esa resolución se aprobó con 57 votos a favor, 14: en contra y! 17 abstenciones, entre las cuales se cuenta la de la Unión Soviética.

${ }^{29} \mathrm{Tal}$ vez, por influencia de la posición latinoamericana, también Asia y África comienzan a manifestar criterios favorables a la extensión de las jurisdicciones nacionales hacia zonas marinas más extensas. Ceylan, la República de Corea, la India, Paquístán, la República de Vietnam, la República del Congo, Cameron, Gabon, Ghana; Guinea, Nigeria y' Senegal; han establecido en sus legisláciones maritimas zonas jurisdiccionales que van desde las 15 hasta las 200 millas marinas. 
presa controla todas las fases de la industria respectiva, incluyendo la producción, refinación, procesamiento, fabricación de los productos finales y distribución a los consumiclores. El lema de la Anaconda, "de las minas al consumidor", da una idea adecuada de la forma en que estas empresas conducen sus operaciones. Ellas poseen tạnbién una posición preeminente en los mercados mundiales, que no es fácil de desafiar cuando un país decide nacionalizar la empresa. Si la actividad nacionalizada es relativamente competitiva, los fabricantes o consumidores tratarán de acudir a otros proveedores. Si el sector nacionalizado tiene una posición monopólica, los fabricantes o consumidores tratarán de mantener la integración vertical, ya sea reteniéndolo, o desarrollando fuentes alternativas de abastecimiento controladas por ellos. Los países latinoamericanos deben pesar cuidadosamente las consecuencias y perspectivas de las medidas que adopten en este sentido.

Una segunda zona de convergencia para las políticas exteriores de los países latinoamericanos radica en sus relaciones comerciales con el resto del mundo. Es bien conocido el activo papel que han desempeñado los países latinoamericanos en la UNCTAD, a través del Grupo de los 77, particularmente a partir de la Reunión de Alta Gracia. También son bien conocidos los principales planteamientos realizados en este plano. En el campo de las materias primas, los países latinoamericanos han luchado con el resto de los países del Tercer Mundo por facilitar su acceso a los mercados internacionales, lograr la adopción de políticas sobre estabilización de precios; organizar sistemas de comercialización $\mathrm{y}^{\prime}$ distribución adecuados; defender la competividad de los productos naturales, y promover la diversificación de sus exportaciones. En cuanto a los productos manufacturados y semimanufacturados, la atención se ha concentrado en los problemas relativos a las preferencias generales, en la reducción de los obstáculos de carácter no arancelario, en la eliminación de las prácticas comerciales restrictivas y en la adopción de medidas encaminadas a modernizar la estructura industrial de estos paises. En vísperas de la UNCTAD III, representantes de los países en desarrollo pertenecientes a tres continentes se runieron en la Segunda Conferencia de Ministros del Grupo de los 77, que turo lugar en Lima en noviembre de 1971, elaboranclo un programa de acción y aprobando la Declaración de Lima. En ésta no se mencionan los programas de ayuda externa de carácter financiero, sino que se pone énfasis en la cuestión de la vinculación de los derechos especiales de giro con el financiamiento del desarrollo, en la implantación y ampliación del sistema de preferencias generales y en la formulación de programas sobre estabilización de precios, apertura de mercados y diversificación de exportaciones. Con anterioridad a esta Reunión, 
los países latinoamericanos habían coordinado sus puntos de vista en una reunión especial de GECLA, que se efectuó en la misma ciudad en el mes de octubre de ese año.

Sin embargo, las estrategias perseguidas por los países latinoamericanos en el seno de la UNCTAD o a través de otros mecanismos de negociación internacional se han visto sobrepasadas por los acontecimientos desencadenados por la crisis energética, cuyos efectos se han extendido en desigual medida al resto de los productos básicos. Los efectos combinados del extraordinario aumento de la demanda de hidrocarburos inherente al estilo de vida de las sociedades industrialmente avanzadas, el grado de organización alcanzado por los productores dentro del marco de la OPEP y la situación conflictiva en el Oriente Medio, determinaron que entre 1970 y 1974 se quintuplicaran los precios de exportación del petróleo y sus derivados. Estimaciones provisionales efectuadas por la OEA indican que los ingresos petroleros de los exportadores netos latinoamericanos -Venezuela, Ecuador, Trinidad y Tobago y Bolivia- aumentarán el $176 \%$ durante el presente año, elevándose de 4.500 millones de dólares en 1973 a 12.450 millones en 1974, de los cuales 11.200 millones corresponderán a Venezuela, 595 millones a Ecuador, 540 a Triniclad y Tobago y 120 a Bolivia. Este fenómeno viene a imprimir un dinamismo inusitado a tendencias ya observables en años anteriores. En efecto, en 1973 los ingresos de la región por concepto de exportaciones aumentaron en $44 \%$ en comparación con un aumento de $19 \%$ en 1972. Esto se debió principalmente a la: elevación de los precios, ya que el valor unitario de las exportaciones registró un alza de $34 \%$ en 1973 en comparación con un $15 \%$ durante el año anterior. Pese a que el valor unitario de las importaciones subió a un $19 \%$ en 1973 , erosionando parte de esos avances, los términos de intercambio y el poder de compra de las exportaciones en 1973 mejoraron un $13 \%$ y un $21 \%$, respectivamente, en circunstancias de que las cifras correspondientes a 1972 fueron del $7 \%$ y $11 \%{ }^{30}$. Estos acontecimientos plantean una indudable posibilidad de revertir o atenuar el proceso secular de deterioro de los términos de intercambio que ha padecido América Latina. Como expresara un vocero de la Reunión de la OPEP, celebrada en Ecuador en junio de 1974, en un mundo que mantiene un ritmo anual de inflación del orden del $12 \%$, "tenemos que comprar mañana lo mismo que podríamos comprar ayer con el precio de un barril de petróleo".

Sin embargo, esta posibilidad no deja de ser cuestionable. En primer lugar, debido a la desigual dotación de recursos de los países

so América tratina en un contexto de Grandes Mrutaciones Internacionales, anticipo del Capítulo I del Estudio Económico de América Latina, 1973, de la CEPAL, págs. 32 a 34. 
en desarrollo, las mismas tendencias alcistas que son fuente de ventajas para unos, imponen desembolsos adicionales a otros. Los participantes de la Reunión de la OPEP, anteriormente mencionada, recibieron una clelegación de los países no alineados encargada de hacer presente los graves perjuicios que afrontan sus economías por causa cle los altos precios del petróleo. In el caso de América Latina, los importadores netos de petróleo gastarán en este producto 3.795 millones de dólares en 1974t en comparación con una cifra de 1.385 millones del año anterior, lo que representa un incremento de $174 \%$. Cabe formular la misma observación, si se toman en cuenta los intereses de países exportadores de trigo como la República Argentina, frente a las intervenciones en que el presidente de Argel y el ministro de recursos naturales de Ecuador expresaron su preocupación por el aumento del precio de este producto, clurante la sesión extraordinaria de la Asamblea General de las Naciones Unidas consagrada al problema de los productos básicos. Esto concluce a una segunda observación, referente a las diferencias que tenderán a registrarse en la posición relativa de los distintos países en desarrollo en el mercado internacional de acuerdo con la naturaleza de sus principales procluctos de exportación, en clesmedro de los exportadores de productos renovables y no estratégicos. Tales interrogantes relegan a un tercer lugar la conocida preocupación con respecto al comportamiento de la demanda y la oferta de productos básicos en el futuro mediato, particularmente si se da crédito a la capacidad de los países inclustrializados para responder a estos morimientos alcistas mediante innovaciones tecnológicas que permitan nuevas sustituciones, transformando sus estructuras productivas e incluso modificando sus propios estilos de vida. Por eso, en la sesión especial cle las Naciones Unidas, varias veces mencionada, el secretario de estado de los Estados Unidos observaba que "si los débiles recurren a la presión, lo harán arriesgando la prosperidad mundial, $y$ provocando de esta manera la desesperación", y a continuación advertía que "la organización de un grupo de países como un bloque tarde o temprano producirá la organización cle las víctimas potenciales en un bloque contrario".31

Si se observa con moderado cinismo la evolución de las relaciones económicas internacionales durante los últimos decenios se llega a la conclusión, sin embargo, que en la medida en que han sido aplicadas inteligentemente estas presiones han demostrado ser el único instrumento eficaz para obtener ciertas concesiones $\mathrm{y}$ mejorar los términos de estas relaciones. Queda abierta la pregunta acerca de

31 Discurso del secretario de estado de los Estados Unidos, señor Henry A. Kissinger, ante la VI Sesión Especial de la Asamblea General de las Naciones Uniclas, New York, 15 de abril de 1974. 
en qué medida la experiencia de la OPEP podría aplicarse a otros productos o sectores. En todo caso, es indudable el efecto de demostración que tiene esta experiencia. El Comité de Países Exportadores de Cobre y la Asociación Internacional de la Bauxica tratan d.e robustecer sus posiciones y buscan coordinarse con la OPEP a fin de consolidar una línea de acción común para estos tres productos. En otro plano, la guerra del banano desatada entre los países latinoamericanos exportadores de este producto y la Standard Fruit ha dado lugar a una propuesta para establecer 'una organización de productores de banano. Con todo, la experiencia es lo suficientemente significativa como para sembrar la sospecha de que en el futuro la situación de los productos básicos dependexá cada vez menos de las fluctuaciones de la oferta y la demanda y cada vez más de la capacidad que demuestren los países productores para concertarse y ejercer una acción política en los mercados internacionales.

Una tercera zona de convergencia que se desea destacar en este ensayo es la que se refiere al tratamiento o control del flujo de recursos externos. Una vez más, el tema ha sido objeto de investigaciones tan lúcidas y pomenorizadas y es tan ampliamente conocido, que nos exonera de entrar en su substancia para limitarnos a señalar la evolución reciente en las políticas de los países de la región en este campo y sus crecientes coincidencias.

La influencia de la inversión extranjera en el proceso de desarrollo de los países no guarda proporción con su participación en el proceso de inversión global que, en el caso de América Latina, no pasó del $5 \%$ durante el último decenio. Ello se debe a la tendencia de dichas inversiones a concentrarse en los sectores más dinámicos de las economías $y$, dentro de ellos, sólo en determinadas ramas productivas y sólo en las empresas de mayor envergadura. Ello explica que la distribución sectorial de la inversión extranjera en América Latina haya evolucionado de las actividades tradicionales (agricultura tropical, minería y petróleo, y servicios públicos) hacia nuevos sectores (industria manufacturera y servicios comerciales y financieros). Esta concentración se acentúa clebido a la tendencia de la inversión extranjera a radicarse en industrias con altas barreras al ingreso de nuevos productores. El resultado es que en Argentina, por ejemplo, entre 1961 y 1966 más de la mitad de las ventas de las 50 firmas más importantes del país fueron hechas por subsidiarias de compañias extranjeras ${ }^{32}$. Estudios recientes relativos a otros países arrojan resultados no muy diferentes ${ }^{33}$. No obstante ello, llama la

32Aldo Ferrer, El capital extranjero en la economía argentina, Trimestre Económico, No 150, 1971.

33Ver Fernando Fajnzylber, Sistema Industrial y Exportación de Manufacturas: Análisis de la experiencia brasilera, CEPAL, noviembre de 1970 y Carlos Bazdzcsch 
atención la despreocupación generalizada que, excepto en el período más reciente, se observa en América Latina con respecto al papel de la inversión extranjera tanto en el plano de las políticas públicas como en el de la investigación académica. Citanclo un trabajo de la CEPAL que data de 1954, French-Davis recuerda que este organismo centró su preocupación en otros aspectos del desarrollo, limitándose en general a señalar la necesidad de "impulsar las inversiones de capital del exterior a fin cle acelerar el ritmo del desarrollo latinoamericano". Es por eso que:

"En general se puede afirmar que los países latinoamericanos no han tenido una "política" frente a la inversión extranjera; esto es, un conjunto coherente y estable de proposiciones y acciones para tratar con el capitalista foráneo. Esa política estuvo ausente hasta en un instrumento potencialmente tan importante como el Tratado de Monterideo, que contiene sólo una breve referencia general a ella en uno de sus artículos. Sin embargo, han habido acciones aisladas. Así, por ejemplo, la mayoría de los países han cerrado algunos sectores específicos al capital extranjero, como por ejemplo el petróleo, los ferrocarriles y la energía eléctrica. En el resto de sus economías, algunos países han mantenido libre la entrada y otros han adoptado en principio una política de admisión selectiva, aunque en la práctica se hizo generalmente muy poco..$^{8 . t}$

De allí que hasta fines de la pasada década poco se supiera acerca del comportamiento y los efectos del capital extranjero en América Latina, ya sea desde el punto de vista de su contribución al conocimiento tecnológico, en adición a sus aportes financieros; su impacto sobre el proceso de sustitución de importaciones o sobre la promoción de exportaciones de manufacturas; los pagos por concepto de patentes, regalías y asistencia técnica, y sus efectos sobre los balances de pagos; el crédito externo obtenido por filiales de firmas extranjeras y su endeudamiento en el mercado interno; sus formas de asociación con el capital local, etc. Fue precisamente a fines del decenio cuanclo se emprende un conjunto de -estudios -iniciados en el caso de Colombia y posteriormente extendidos a todo el Pacto Andino- que, al arrojar nueva luz sobre estos problemas, permiten formular nuevas políticas relacionadas con el flujo de capi-

Parada, La Politica Aclual hacia la inversión extranjera directa, Comercio Exterior, México, noviembre de 1972.

34Ricardo French-Davis, Foreign Investment in Latin America: recent trends and prospects, en Victor L. Urquidi y' Rosemary Thorpe (editores), Latin America in the International Economy,, 1973, pág. 175. 
tales y tecnología extranjeros. Estas políticas tienclen a mostrar rasgos similares, incorporados primeramente en la Decisión 24 adoptada en 1970 por el Grupo Andino, y posteriormente en la ley sobre creación del Instituto Nacional de Propiedad Industrial del Brasil, en diciembre del mismo año; en la ley sobre Comercialización de tecnología promulgada en la República Argentina en 1971, y en la legislación mexicana sobre inversiones extranjeras de 1972. ${ }^{35}$

El común denominador de estas políticas parece ser la búsqueda de un mayor control sobre la importación de capitales y tecnología, que permita conciliar el aporte de estos factores externos con los objetivos del desarrollo nacional. Sin intentar reseñar sus semejanzas y diferencias, y reconociendo que estas últimas suelen ser significativas, cabe afirmar que en general dichas políticas se proponen (a) fortalecer la posición negociadora del capital nacional frente a la inversión extranjera; (b) influir en la orientación sectorial de la inversión extranjera mediante la adopción de critexios más selectiros al respecto; (c) evitar que el impacto de la inversión extranjexa se limite a sus aportes financieros asegurando que éstas realicen una contribución significativa desde el punto de vista del desarrollo tecnológico, la capacidad administrativa o la ampliación de los mercados externos del país; (d) permitir la desagregación del "paquete" que suele ir envuelto en la inversión extranjera clesde el punto de vista de los elementos financieros, tecnológicos, de comercialización y' gerenciales; (e) controlar su impacto sobre el balance de pagos del país regulando la repatriación de capital y utilidades y los pagos por concepto de regalías, patentes $\mathrm{y}$ asistencia técnica; ( $f$ ) controlar su gravitación sobre la economía del país mediante regulaciones relativas a la reinversión de utilidades $y^{\prime}$ a la compra de empresas nacionales, etc. En el caso de una agrupación subregional, como el Grupo Andino, estas políticas buscan además evitar una excesiva competencia entre los países miembros por la atracción de inversiones extranjeras; lograr una distribución equitativa de dichas inversiones entre los distintos países, y fortalecer la inversión local, particularmente mediante la promoción de empresas multinacionales de carácter regional.

Es interesante observar como la legislación de un país aparentemente poco "dirigista", como el Brasil, tiene por objeto "adoptar, con vistas al desarrollo económico del país, medidas capaces de acelerar y regular la transferencia de tecnologia y establecer mejores

35Para el examen de las tendencias recientes en esta materia, ver Constantine $V$. Vaitsos, The changing policies of Latin American Governments toward Economic Development in Direct Foreign Investment, manuscrito fechado en abril de 1973, cuya versión española fue publicada por El Trimestre Económico. 
condiciones de negociación y de utilización de las patentes"sa, y' contempla programas orientados "al fortalecimiento del poder nacional de negociación y selección de importación de tecnologías" y' a "organizar y operar instrumentos selectivos de importación de técnicas" ${ }^{37}$. Debe advertirse que el Instituto de Propiedad Industrial del Brasil, es uno de los organismos más eficaces en este campo.

En el espectro de las preocupaciones latinoamericanas en torno a estos problemas merece capitulo especial el comportamiento e influencia de las corporaciones multinacionales. Ello no es de extrañar; si se tiene en cuenta que dichas empresas representan alredeclor de las dos terceras partes de la inversión extranjera radicada en el mundo no socialista, es clecir, unos 165 mil millones de dólares y' que las ventas de sus filiales en el extranjero suman más de 330 mil millones de clólares, lo que implica una participación del orden del $30 \%$ en el comercio internacional. Otro orden de magnitud lo proporciona el hecho de que sus activos líquidos alcancen un rolumen de 250 mil millones de dólares, lo que representa el triple de las reservas monetarias internacionales combinaclas de los Estados Unidos, la Comunidad Económica Europea y el Japón. Por otra parte, las corporaciones transnacionales tienen prácticamente el monopolio de la innovación tecnológica en el munclo. En el caso de América Latina, hacia 1966 las ventas de las subsidiarias de empresas norteamericanas en el área alcanzó un valor de 6.000 millones de dólares en comparación con el nivel alcanzado por las exportaciones norteamericanas hacia la región, que en ese fueron de 4.500 millones. Los cancilleres latinoamericanos incluyeron el tema en las "bases para el diálogo" que elaboraron para la Reunión de Tlatelolco, y la región ha tenido una participación activa en la elaboración del informe sobre El Impacto de las Corporaciones Multinacionales sobre el Desarrollo y las Relaciones Internacionales, preparado por un grupo de personas eminentes, en cumplimiento de la Resolución 1.721 (LIII) del Consejo Económico y Social de la Organización.

Como se ha dicho, resulta problemático ponclexar la fortaleza o fragiliclacl del consenso alcanzaclo en torno a algunas cle estas tesis y formular vaticinios al respecto. Sin embargo, si el consenso y'a alcanzado con respecto a ellas se mantiene, y si los países latinoamericanos son capaces de superar los oligopolios verticales que limitan su capacidad de utilizar sus propios recursos naturales, si son capaces de articular con moderación e inteligencia presiones políticas en defensa de sus productos primarios, y si tienen la coherencia de aplicar siquiera en una razonable medida las políticas adoptadas en el período

30Ley No 5.648 del 11 de diciembre de 1970, por la cual se crea el Instituto Nacional de Propiedad Industrial.

siPrograma del Instituto Nacional de Propiedad Industrial de 1973. 
reciente para controlar el flujo cle recursos extranjeros, todo indica que estarán en condiciones de mejorar su participación internacional. Como puede apreciarse, los condicionales son muchos y los resultados, aleatorios.

5. EL GRADO Y ORIENTACIÓN DE LAS RELAGIONES RECÍPROCAS ENTRE LOS PAÍSES DE LA REGTÓN

La tercera variable propuesta en este trabajo para examinar la evolución hacia un subsistema regional latinoamericano se refiere al grado y orientación de las relaciones interlatinoamericanas, esto es, cle la interacción existente entre los países de la región.

En efecto, no basta con verificar la forma en que han operado las dos variables anteriores. Es perfectamente posible concebir un conjunto de países dotados de una común conciencia de su identidad frente al resto del mundo -conciencia que incluso puede haber sido acicateada por una situación de conflicto o insatisfacción en determinados aspectos de sus relaciones exteriores - y cuy'as políticas externas tengan un grado apreciable de coherencia y coordinación, pero cuyas relaciones recíprocas sean mínimas como consecuencia de que sus relaciones económicas, políticas y culturales estén orientadas preponderantemente "hacia afuera" esto es, hacia sus ex metrópolis o hacia los grandes centros del poder mundial. Estimamos que para que una agrupación regional se asiente sobre bases sólidas y duraderas -y pueda constituir un subsistema regional- es necesario que la interacción entre los países participantes alcance un grado o nivel razonable.

Pero no es suficiente verificar el grado de interacción entre los países miembros del grupo, sino que es necesario también cleterminar la orientación de sus relaciones reciprocas, pudiéndose formular distinciones según prevalezcan entre ellos relaciones de cooperación o relaciones de conflicto. Parece lógico esperar que sólo en el primer caso estariamos en presencia de un subsistema regional que, por haber escogido un camino solidario, podría desarrollar un comportamiento homogéneo con probabilidades de continuidad en el sistema internacional.

Aunque el examen de estas relaciones escapan a los límites de este trabajo, es posible comprobar que existe creciente interés entre los países de la región por los mercados, las oportunidades de inversión y las perspectivas de cooperación económica en el plano interlatinoamericano. De ello da testimonio la proliferación de convenios 
comerciales, proyectos multinacionales de infraestructuras o de aprovechamiento de recursos naturales $\mathrm{y}$ empresas bi o multinacionales latinoamericanas.

A este úitimo respecto, la subsistencia de obstáculos al comercio intrarregional, particularmente en el sector de las manufacturas, $y$ la importancia asignada por los países de la región al desarrollo industrial, permiten anticipar que los esfuerzos encaminados a la expansión clel comercio entre los países de la región serán emulados en breve por ambiciosos programas de cooperación industrial. Al fin $y$ al cabo, no se trataría sino cle iniciar en América Latina una experiencia mundial, de conformidacl con la cual a la internacionalización del comercio siguió la de la producción: la mejor manera de superar las barreras que se oponen al incremento de las exportaciones hacia un país determinado consiste en realizar en dicho país las inversiones necesarias para manufacturar en él los respectivos productos. Ya sea que la utilización de los acuerdos de complementación dentro del marco de la ALALC conduzcan a la formación de empresas mixtas, o que éstas puedan requerir de dichos acuerdos para asegurar el acceso de sus productos a los mercados de terceros países, parece visible la existencia de una gran preocupación e interés por estos temas. Esta preocupación plantea el problema del tratamiento que cada país otorga a sus inversores en el exterior o a las inversiones que se radican en él, de origen latinoamericano.

También resulta evidente el interés de los países mayores por sus vecinos de menor desarrollo relativo. Junto a las relaciones que desde antiguo han venido desarrollando los países del cono sur - relaciones que muestran signos recientes de intensificación - comienzan a evidenciarse aproximaciones similares en otras regiones, como el área del Caribe. La primera de las zonas anteriormente mencionadas presenta un número considerable de proyectos multinacionales de gran envergadura, de distinta naturaleza y alcance, si bien en su mayor parte se trata de proyectos de infraestructura. Tal vez el de mayor calibre sea el proyecto hidroeléctrico de Itaipú, entre Brasil y Paraguay', que representará una inversión final cercana a los 5.000 millones de dólares. Paralelamente se ha adelantado, entre Argentina y Paraguay, un proyecto que contempla la generación de energía hidroeléctrica y obras de navegación en el curso cle los ríos Yaciretá y Apipé. Por otra parte, Argentina y Paraguay han negociado recientemente acuerdos no extensibles en varios sectores productivos. En otro plano, Argentina y Uruguay han daclo comienzo conjuntamente a las obras de Salto Grande, han programado estudios sobre el régimen del Rio de la Plata que incluye la identificación de posibilidades de desarrollo en los sectores productiyos, e incluso han anticipado la posibilidad de celebrar un acuerdo de alcance subregional, posible- 
mente encuadrado dentro del marco jurídico de la ALALC. En los estudios sobre el potencial del Río Uruguay, participan tanto este último país como Argentina y Brasil. Bolivia también ha siclo objeto de consultas y convenios encaminados al desarrollo del sector de los transportes, la minería y algunas ramas productivas, entre los cuales los más importantes son los convenios celebrados entre Bxasil y'Bolivia respecto del gas natural y el desarrollo del hierro en este último país. En el ámbito del Caribe, los países ribereños de mayor dimensión económica miran con interés a las oportunidades de intercambio e inversión en el área, exploran la posibilidad de establecer fórmulas de asociación entre los diversos esquemas de integración que convergen en la zona (Grupo Andino, Mercado Común Centroamericano y CARMFTA) así como entre estos esquemas y los países no asociados a ninguno de ellos. ${ }^{38}$

Los tres paises mayores a su vez miran hacia el Grupo Andino, estableciendo relaciones ya sea a nivel de la subregión, mediante la constitución de comisiones mixtas, o en forma bilateral con los países que la integran. Este interés quedó en evidencia con ocasión de la instalación de las comisiones mixtas andino-argentina $y^{\prime}$ andino-mexicana, clurante el X Período de Sesiones Ordinarias de la Comisión del Acuerdo de Cartagena, en noviembre de 1972, así como con la gira del canciller Gibson Barbosa, del Brasil, por países del Grupo Andino durante 1973.

Uno de los ejemplos más recientes, y a la vez más destacados, de solidaridad regional son los planes venezolanos para utilizar una parte de los recursos adicionales provenientes de sus exportaciones petroleras para la constitución de fondos colocados bajo la administración de organismos regionales o subregionales de financiamiento del desarrollo; la compra de bonos y participaciones en los préstamos otorgados por los organismos internacionales; la apertura del mercado venezolano a emisiones de bonos de los países de mayor desarrollo relativo de la región, especialmente para aquellos proyectos que fortalezcan la integración latinoamericana, estimulen la presencia de América Latina en los mercados internacionales y hagan posible la realización de proyectos multinacionales latinoamericanos, y la realización de inversiones directas en este tipo de proyectos localizados en paises de menor desarrollo. Estos hechos constituyen otros tantos ejemplos de la renorada preocupación de los países latinoamericanos por los problemas de la región.

Resultaría de especial interés -aunque escapa con mayor razón

3sVer Héctor Hurtado, El Caribe y Vencizucla, Integración de la Integración, documento presentado a la Conferencia para la Colaboración Económica y Cultural del Caribe (COLABOR), celebrada en Bogotá en marzo de 1974, y publicado en

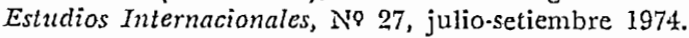


Luciano Tomassini / Tendencias farorables o adversas a la formación...

a los límites de este trabajo- examinar la evolución de los movimientos de integxación existentes en América Latina, sus crisis, sus resultados y, sobre todo, sus perspectivas. Junto a programas promiso. rios de integración regional -o de alcance subregional como en el caso del Grupo Andino- aparecen experimentos de integración sectorial, ya sea por productos o sobre bases diferentes, con alentadores resultados. Al mismo tiempo, se advierte la preocupación por im. pulsar un proceso de convergencia entre los distintos esquemas y agrupaciones de países existentes en la región. En la VI Reunión de Cancilleres de la Cuenca del Plata el presidente del país anfitrión, la República Argentina, aprovechó la oportuniclad para formular algunas reflexiones que podrían extrapolarse al proceso de integración de América Latina y expresar su concepción acerca cle ese proceso, concepción que en gran medida es comparticla por otros países, al manifestar:

"Quiero hacer una reflexión sobre lo que considero debe ser el contexto en que debieran desarxollarse las relaciones internacionales en la Cuenca del Plata. Hasta nuestros días la forma más clásica de las relaciones internacionales ha sido la bilateral, la que contrapone los intereses de un Estado con los cle otro Estado, de un Gobierno con los de otro Gobierno. No creo que la suma de esas relaciones bilaterales entre nuestros cinco países puieda ser el marco adecuado en que deben desarrollarse las relaciones económicas, sociales y' culturales del ánea. Esas relaciones políticas, económicas $y$ culturales deben coordinarse en función de los intereses cle los cinco países, en su conjunto, y no como resultado de los acuerdos bilaterales cle los países que componen la Guenca del Plata".,9o

¿Qué es lo que induce a los países a adoptar por la vía del bilateralismo y de la competencia o a inclinarse por fórmulas que enfaticen la cooperación y la solidaridad en sus relaciones internacionales?

El presidente Perón, en esa oportuniclad constataba que "aún hoy en día existe la preocupación de lo que podemos ganar o perder en nuestro quehacer económico cliario". Y reconocía que "es lógico y natural que así sea".

No es difícil concordar en que los países latinoamericanos miran con mayor interés hacia la propia región -incluyendo aquellos países que tradicionalmente han seguiclo caminos más independientes o solitarios $-y$ en que estamos en presencia de una notoria reactivación de

$\because \quad$ 30Discurso del Presidente de la República Argentina, Teniente General Juan Domingo Perón, en la sesión inaugural de la VI Reunión de Cancilleres de los Países de la Cuenca del Plata, 10 de junio de 1974. 
las relaciones intralatinoamericanas. Pero, como es natural, este proceso lleva en sí gérmenes de cooperación y de conflicto. Resulta difícil apreciar en qué medida y oportunidades los países optarán por una vía solidaria -en cuya apertuxa es fundamental el pajel que pueden jugar los procesos de integración-o por caminos que acentúen los elementos competitivos en sus relaciones recíprocas. Lo que ocurra dependexá del balance anticipado que esos mismos países hagan de las ganancias que podrian obtener en una y otra alternativa. Este balance no se ha intentado, y seguramente no sería posible hacerlo sino sobre bases extremadamente desagregadas y pragmáticas, pero es importante tener presente que la opción existe a fin cle poder ponderarla cuando se trate de adoptar decisiones específicas.

La formación de un subsistema regional latinoamericano, que permita asentar el desarrollo de nuestros países sobre bases adecuadas y mejorar sus condiciones de participación en el sistema internacional, dependerá en gran medida de la orientación que adopten sus relaciones recíprocas.

Seguramente las decisiones adoptadas por las potencias industriales y las corporaciones internacionales continuarán tenienclo una gravitación excesiva en los países de la región, los intereses foráneos o transnacionales continuarán desencadenando presiones en los sectores claves de su política exterior, y los países latinoamericanos continuarán experimentando limitaciones clerivadas de su insuficiente conocimiento de la tecnologia o de las reglas de juego que imperan en ellos. Pero la consolidación de un subsistema regional latinoamericano, sobre bases solidarias, permitiría un mayor grado de "nacionalización" de sus comportamientos exteriores o, al menos, el inicio de un modesto proceso de "sustitución de importaciones" en relación con las decisiones que afectan su política exterior. 